\title{
Experimental and Numerical Investigation on the Thermal and Mechanical Behaviours of Thermal Barrier coatings Exposed to CMAS Corrosion
}

\section{Dongxu Li}

Xianjiaotong University https://orcid.org/0000-0002-6080-6749

\section{Peng Jiang}

Xi'an Jiaotong University

\section{Renheng Gao}

Gas Turbine Research Establishment

\section{Fan Sun}

Xi'an Jiaotong University

Xiaochao Jin ( $\nabla$ jinxiaochao@stu.xjtu.edu.cn )

Xi'an Jiaotong University https://orcid.org/0000-0002-1604-7757

\section{Xueling Fan}

Xi'an Jiaotong University

\section{Research Article}

Keywords:

Posted Date: November 6th, 2020

DOI: https://doi.org/10.21203/rs.3.rs-101300/v1

License: (1) This work is licensed under a Creative Commons Attribution 4.0 International License. Read Full License

Version of Record: A version of this preprint was published at Journal of Advanced Ceramics on March 10th, 2021. See the published version at https://doi.org/10.1007/s40145-021-0457-2. 


\section{[Title Page]}

\section{Experimental and numerical investigation on the temperature and stress fields in the suspension plasma sprayed thermal barrier coatings exposed to CMAS corrosion}

Dongxu Li $\mathrm{L}^{\mathrm{a}}$, Peng Jiang ${ }^{\mathrm{a}}$, Renheng Gao ${ }^{\mathrm{b}}$, Fan Sun ${ }^{\mathrm{a}}$, Xiaochao Jin ${ }^{\mathrm{a}, *}$, Xueling Fan ${ }^{\mathrm{a}, *}$

${ }^{\text {a }}$ State Key Laboratory for Strength and Vibration of Mechanical Structures, School of Aerospace Engineering, Xi'an Jiaotong University, Xi'an, China ${ }^{\mathrm{b}}$ AEEC Sichuan Gas Turbine Establishment, Chengdu 610500, China

Correspondence information: Xiaochao Jin, State Key Laboratory for Strength and Vibration of Mechanical Structures, School of Aerospace Engineering, Xi'an Jiaotong University, No. 28 Xianning West Road, Xi'an, Shanxi, 710049, P.R. China, E-mail: jinxiaochao@stu.xjtu.edu.cn.

Tel. no.: +86-29-82667686, Fax no.: +86-29-82669044

Xueling Fan, State Key Laboratory for Strength and Vibration of Mechanical Structures, School of Aerospace Engineering, Xi'an Jiaotong University, No. 28 Xianning West Road, Xi'an, Shanxi, 710049, P.R. China, E-mail: fanxueling@mail.xjtu.edu.cn.

Tel. no.: +86-29-82667686, Fax no.: +86-29-82669044 


\title{
Experimental and numerical investigation on the thermal and mechanical behaviours of thermal barrier coatings exposed to CMAS corrosion
}

\author{
Dongxu $\mathrm{Li}^{\mathrm{a}}$, Peng Jiang ${ }^{\mathrm{a}}$, Renheng Gao ${ }^{\mathrm{b}}$, Fan Sun ${ }^{\mathrm{a}}$, Xiaochao Jin ${ }^{\mathrm{a}, *}$, Xueling Fan ${ }^{\mathrm{a}, *}$ \\ ${ }^{a}$ State Key Laboratory for Strength and Vibration of Mechanical Structures, School of Aerospace \\ Engineering, Xi'an Jiaotong University, Xi'an, China \\ ${ }^{b}$ AEEC Sichuan Gas Turbine Establishment, Chengdu 610500, China
}

\begin{abstract}
Calcium-magnesium-alumino-silicate (CMAS) corrosion is one of the most critical failure mechanisms of thermal barrier coating (TBC). CMAS attack significantly alters the temperature and stress fields in TBCs, resulting in their delamination or spallation. In this work, the dynamic evolution process of suspension plasma sprayed (SPS) TBC under CMAS attack is investigated. The CMAS corrosion leads to the formation of reaction layer and subsequent bending of TBC. Based on the observations, a corrosion model is proposed to describe the generation and evolution of the reaction layer and bending of TBC. Then, numerical simulations are performed to investigate the corrosion process of free-standing TBC and the complete TBC system under CMAS attack, respectively. Results show that the CMAS corrosion has a significant influence on the stress field, such as the peak stress, while it has little influence on the steady state temperature field. It should be noted that the peak of stress increases with holding time which increases the risk of the rupture of TBC. There is a parabolic relationship between the stress and reaction layer thickness in the holding stage. Furthermore, in the traditional failure zone, such as the interface of top coat and bond coat, the stress obviously change during CMAS corrosion.
\end{abstract}

Keywords: Thermal barrier coating (TBC); CMAS corrosion; temperature field, stress field. 


\section{Introduction}

Thermal barrier coating (TBC) is widely used in gas turbines and aircraft engines to protect the metallic substrates and other engine parts from high-temperature exposure. TBC usually consists of four layers, top coat (TC), thermally grown oxide (TGO, a thin layer formed due to oxidation), bond coat (BC), and substrate (Sub) [1-4]. Ceramic TC consisting of porous 7-8\% yttria-stabilized zirconia (YSZ) exhibits excellent thermal insulating performance and shows high resistance to high-temperature corrosion [5]. The YSZ layer is usually deposited by two techniques, air plasm spray (APS) and electron-beam physical vapor deposition (EB-PVD). APS is a low-cost process depositing the YSZ coating with a parallel layered architecture, and EB-PVD deposits the YSZ coating with a microstructure of vertical columnar grains that increases the strain tolerance due to the intercolumnar porosity $[6,7]$. However, both techniques show some drawbacks: EB-PVD is rather expensive for wide-scale use, and APS TBC has typically a shorter thermal lifetime. Recently, a novel thermal spray technique has been developed, suspension plasma spraying (SPS), which might be a processes combining the advantages of both APS and EB-PVD [8]. This low-cost possess can lead to the formation of columnar structures or vertical cracks in the TC which improve strain tolerance of the TBC. Unlike the conventional APS and EB-PVD TBC, the study on failure mechanism of the SPS TBC is quite limited.

The calcium-magnesium-alumino-silicate (CMAS) corrosion is believed to be one critical failure mechanisms which causes the open structure of TBC [9-11]. CMAS is a kind of mixed oxides usually coming from sand, runway debris, volcanic ash, air pollution, or fly ash [14]. The attack from CMAS, including the impact damage caused by large siliceous debris and erosive wear or local spallation caused by small debris [15-19], will cause corrosion of TBC that deteriorates the performance and shorten the lifetime of TBCs. Researches showed that the siliceous particles can penetrate into TBCs due to conspicuous wetting ability when the temperature in TBCs is higher than the melting point of CMAS [15,20,21], deteriorating the thermal insulating performance and increasing the stiffness of TBCs. Moreover, YSZ is partially dissolved 
by CMAS, resulting in a microstructure degradation and phase transformation [22]. The key reason of both these two failure mechanisms is the effection of stress, which will possibly trigger the catastrophic failure of TBCs during their service. Therefore, it is necessary to study the stress of TBCs under CMAS attack.

A number of researches were focused on the chemical reaction mechanism and the evolution of microstructure of TBCs after CMAS attack, which were the basis of further research about stress. Graces et al. [23] studied the corrosion process of CMAS in TBCs. The results proved that molten CMAS dissolutes the YSZ coating at elevated temperature, and then upon saturation, re-precipitation of several crystalline phases closer to equilibrium with the melt, which are the primary mechanism of interaction among corrosion process, resulting in generation of reaction layer or corrosion area. Shan et al. $[24,25]$ particularly elucidated the mechanism of buckling of APS TBC under CMAS attack. Firstly, CMAS becomes soft (around $764{ }^{\circ} \mathrm{C}$ ) and melt (around $1250{ }^{\circ} \mathrm{C}$ ), and infiltrates into pre-existing cracks and pores due to the capillary force drives. Additionally, CMAS seperates inter- or intra-splat boundaries so that the volume of coating tends to increase. The expansion introduces a compressive stress since the top coat is physically constrained by the substrate, which leads to buckling to release compressive stress. The whole buckling process occurs at high temperature. CMAS solidifies gradually and the buckling shape is rather fixed during the cooling process, however, changed due to the thermal expansion coefficient mismatch which tends to increase the bending.

It is well known that the failure caused by stress usually appeared during cooling. Evans et al. [26,27] studied the delamination mechanism of TBCs during cooling, which confirmed that thermal mismatch between corroded ceramic coating, metallic substrate and corrosion area generated compressive stress in the coating. However, the distribution and evolution of stress of TBCs under CMAS attack is also important at high temperature. Zhou et al. [26] established constitutive equations for TBCs under CMAS infiltration and corrosion. Similarly, they observed the bending of free-standing $\mathrm{TBC}$ at high temperature and defined a specific parameter named coefficient of 
corrosion expansion to describe the volume expansion of coating under CMAS attack.

The dynamic evolution of the temperature and stress fields caused by the CMAS attack is challenging to trace, which limits the accurate analysis and prediction of the service life of TBCs. Up to now, few researches on the mechanism of buckling of SPS TBCs, and the temperatue and stress fields of TBC under CMAS attack during the whole corrosion process has been reported [28-30]. In this work, we develop a new method to describe the mechanical behavior of SPS TBCs under CMAS attack, by combining experiments with numerical calculations.

\section{Experiments}

\subsection{TBC preparation}

All TBC samples, 30 in total, were deposited on the Ni-base superalloy substrates machined in the form of a "square button" (5 $\mathrm{mm}$ in width, $3.65 \mathrm{~mm}$ in thickness). TBC (450 $\mu \mathrm{m}$ in thickness) of $7 \mathrm{wt} \% \mathrm{Y}_{2} \mathrm{O}_{3}$ stabilized $\mathrm{ZrO}_{2}$ were deposited by SPS. The substrates were removed by hydrochloric acid, since the metallic substrate can't bear high temperature above $1150{ }^{\circ} \mathrm{C}$. The free-standing TBCs without substrate can be easily deformed,; then phenomena can be observed, such as bending and rupture. Therefore, free-standing TBCs were used to study the corrosion process, which menas that the influence of substrate during CMAS corrosion is ignored.

\subsection{CMAS preparation}

The CMAS is mainly composed of $\mathrm{CaO}, \mathrm{MgO}, \mathrm{Al}_{2} \mathrm{O}_{3}, \mathrm{SiO}_{2}$, with a varied component ratio. This work adopted a component ratio of as 33: 9: 13: 45 (CaO: $\mathrm{MgO}$ : $\mathrm{Al}_{2} \mathrm{O}_{3}: \mathrm{SiO}_{2}$, in mole percentage) [31]. These four oxides were mixed with deionized water and wet grinded for $20 \mathrm{~h}$ to form the homogenous powder. The mixture was dried for $12 \mathrm{~h}$ at $120^{\circ} \mathrm{C}$ in the oven and then dry grinded for $4 \mathrm{~h}$. The powder, set in crucible of aluminium oxide, was heated for $4 \mathrm{~h}$ at $1400^{\circ} \mathrm{C}$ in the muffle furnace and then cooled down to room temperature to obtain the CMAS glass. The CMAS glass was milled into a fine powder with mortar and pestle, and then sieved by a 500 mesh. The milled CMAS was mixed with ethanol to produce a thick paste and then deposited on the TBC. 


\subsection{CMAS corrosion experiments}

Experimental group (TBC with CMAS) and control group (TBC without CMAS) were set in the experiments, respectively. In the experimental group, the TBC was coated with a uniform layer of CMAS paste by brushing and drying, to achieve a CMAS loading of $25 \mathrm{mg} / \mathrm{cm}^{2}$. Corrosion experiments were conducted in a muffle furnace at a temperature of $1400{ }^{\circ} \mathrm{C}$, which is set similarly with the Ref. [32]. The heating rate was set as $5{ }^{\circ} \mathrm{C} / \mathrm{min}$ with an annealing time of $0,4,8,12$ and $24 \mathrm{~h}$, respectively; and then the samples were cooled down to room temperature in static air. The samples were embedded in epoxy for $10 \mathrm{~h}$ after the corrosion experiments and then cut to obtain crosssections. Scanning electron microscopy (SEM, ZEISS EVO10, Germany) was adopted to obtain the micromorphology, and the energy-dispersive spectroscopy (EDS) was utilized to analyze the element distribution in the corrosion zones.

\section{Experimental results}

\subsection{Bending of free-standing TBC}

As shown in Fig. 1(a), the TBC sample with CMAS is obviously bended compared with the one without CMAS after heat treatment at $1400{ }^{\circ} \mathrm{C}$ for $8 \mathrm{~h}$. Similar results were observed for different dwell times, and further comparison indicated that the bending degree of TBCs increased with heating time. Generally, The infiltration of CMAS caused a mismatch of thermal expansion coefficients between infiltrated and noninflitrated layers, which further caused the curvature of the coating to change during cooling. As already clarified, the bending of the coating was not mainly due to the thermal expansion mismatch of the TBC after cooling but the infiltration of CMAS, due to CMAS separate inter- and intra-splat boundaries of YSZ grain at high temperatures [26]. Here, similar results were found within free-standing SPS TBC, as illustrated in Fig. 2. As shown in Fig. 2(a), EDS analysis exhibits the major element composition of the coating. There are two obvious different parts. From the Al element map, it is obvious that the CMAS is concentrated on the top layer. As shown in Fig. 2(b), the microstructure in top layer is obviously different from the bottom layer. From the $\mathrm{Zr}$ element map, it is clear that the amount of $\mathrm{Zr}$ in the top layer reduced. A higher 
magnification image (Fig. 1(b)) indicates that CMAS (indicated by $\mathrm{Mg}$ ) penetrated between the $\mathrm{ZrO}_{2}$ grains. This confirmed that the $\mathrm{ZrO}_{2}$ grains were separated by CMAS, which induced the volume expansion of the reaction layer. The bending degree of TBC over time was also recorded in the experiments, and further analysed in the section 3.3. In the section 4.1, the results will be used to develop the corrosion model.

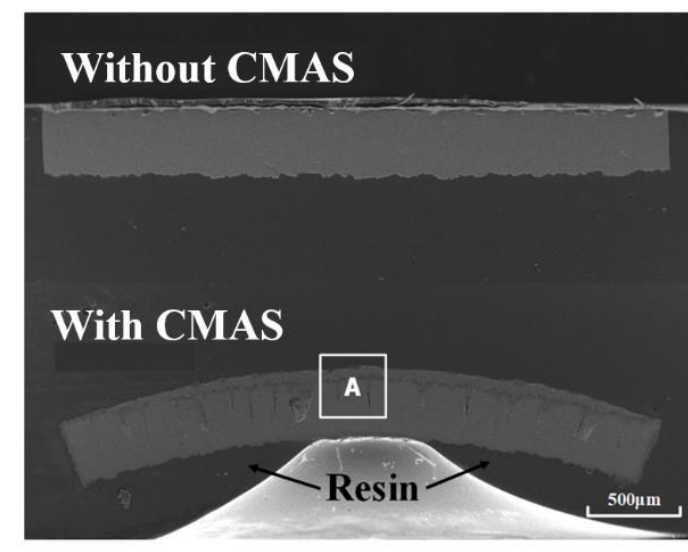

(a)

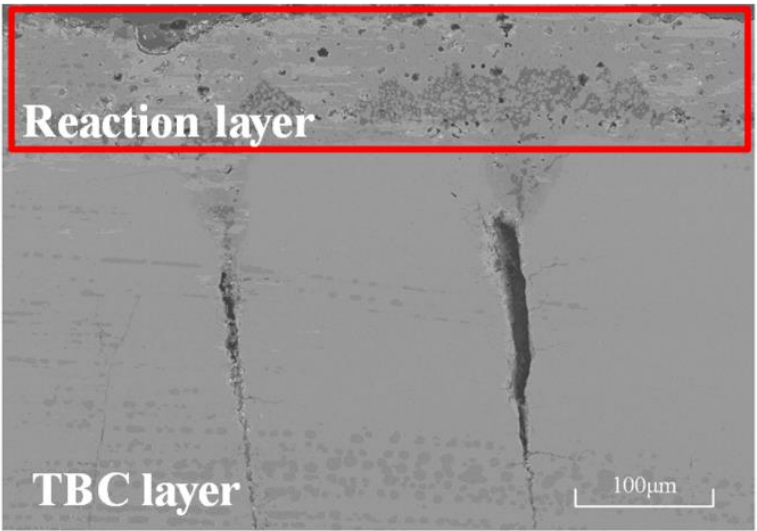

(b)

Fig. 1 (a) Cross-sectional images of the TBC after heat treatment at $1250^{\circ} \mathrm{C}$ for $8 \mathrm{~h}$ without and with CMAS, and (b) micromorphology with higher resolution of area A.
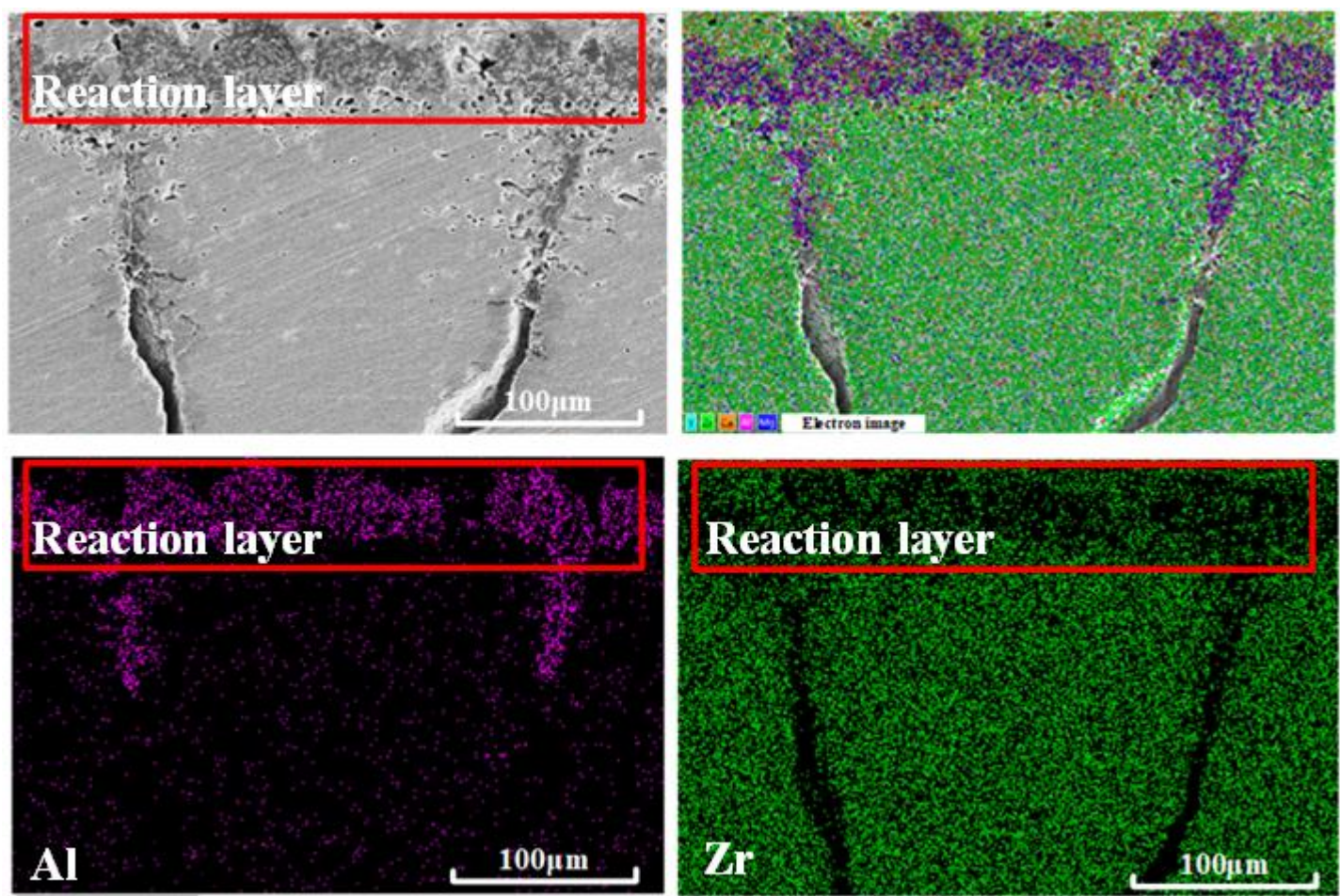

(a) 

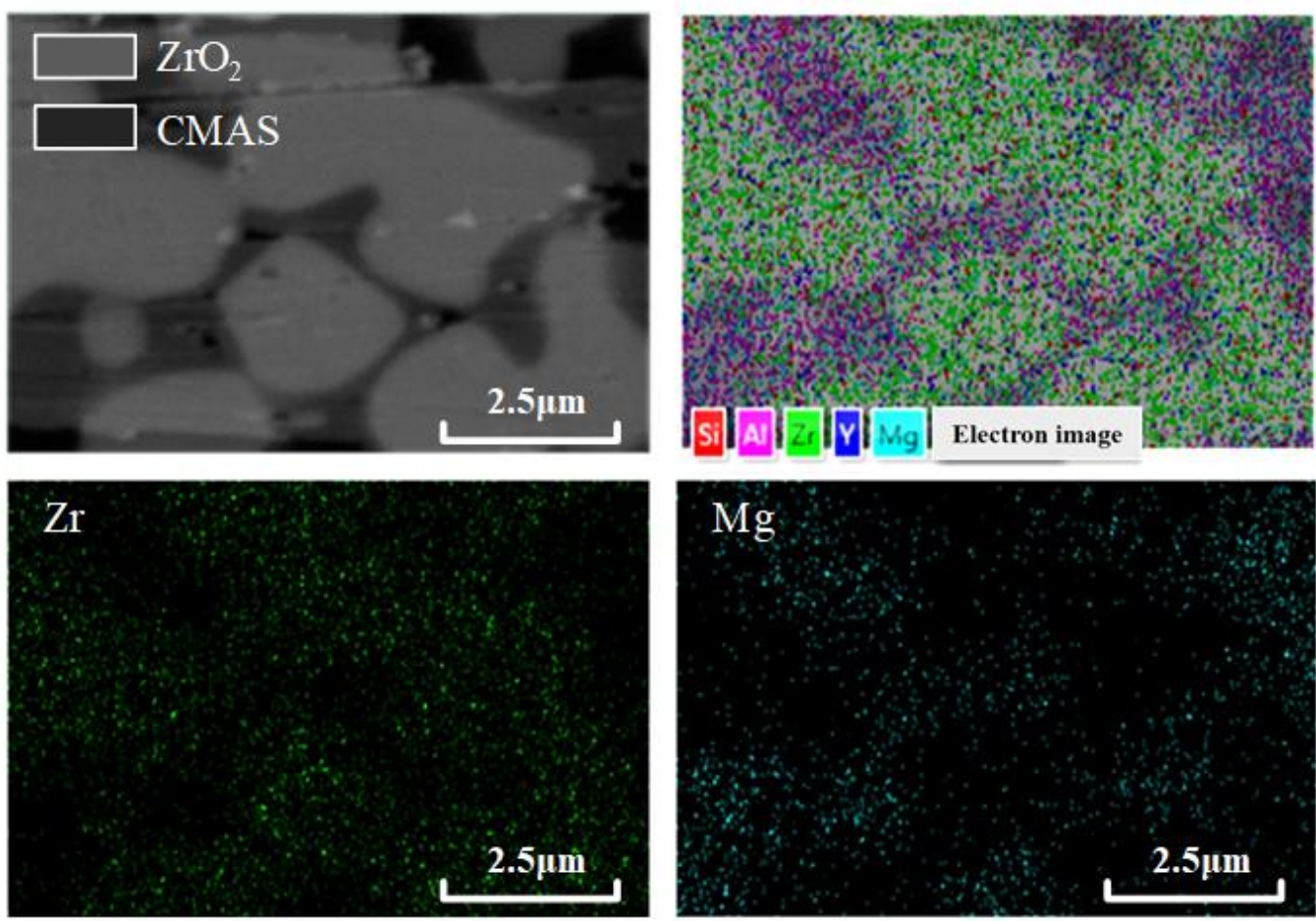

(b)

Fig. 2 EDS images of (a) TBC and (b) reaction layer after heat treatment at $1250^{\circ} \mathrm{C}$ for $12 \mathrm{~h}$ with CMAS.

3.2 The generation of the reaction layer

The microstructural difference of the top layer and another layer is described in the previous section. As shown in Fig. 1(b), the color of top layer is darker than others. Furthermore, the elements distribution also exhibits the distinction of two layers. As illustrated in Fig. 2(a), the elements of CMAS concentrates on the top layer of TBC, and these element distribution maps indicate the area of CMAS infiltration. Researches proved that the reaction of CMAS and TBC happened in the area of infiltration $[23,24,27]$. Therefore, the top layer is defined as the reaction layer. It should be noted that the reaction layer thickness continouly increases with the heat preservation time. And the values were recorded in experiments, which would be further studied in the section 3.3. The material of TC layer of SPS TBCs in the test is 7YSZ, so the reaction mechanism is similar with APS TBCs under CMAS attack. The phase composition of the YSZ coatings remains $\mathrm{t}^{\prime}-\mathrm{ZrO}_{2}$ after the high temperature annealing and CMAS corrosion, which is the same with the as-sprayed sample [33].

3.3 Relationship between the reaction layer thickness and bending degree 
Results confirmed that the bending and the reaction layer generated in the freestanding TBC under CMAS attack. The experimental data are fitted by two empirical equations, i.e., Eq. (1) and Eq. (2), respectively. In the equations, $H_{\text {tor }}$ denotes the reaction layer thickness, $t$ is the dwell time. As shown in Fig. $3, H_{\mathrm{bd}}$ denotes the bending degree of TBCs. The curvature of the coatings was calculated with Eq. (3). It is noted that both the reaction layer thickness and bending degree of TBC increase with the holding time. Therefore, in the next section, the laws are used to construct a simplifed corrosion model to describe the complex process of CMAS attack.

$$
\begin{aligned}
H_{t o r} & =\left(-106 \cdot e^{\left(-\frac{T}{4}\right)}+106\right) \times 10^{-6} \\
H_{b d} & =\left(-45 \cdot e^{\left(-\frac{T}{4}\right)}+45\right) \times 10^{-6} \\
\rho & =\frac{-90 \cdot e^{\left(-\frac{T}{4}\right)}+90}{\left(-45 e^{\left.-\frac{4}{T}+45\right)^{2} \times 10^{-6}+6.25}\right.}
\end{aligned}
$$

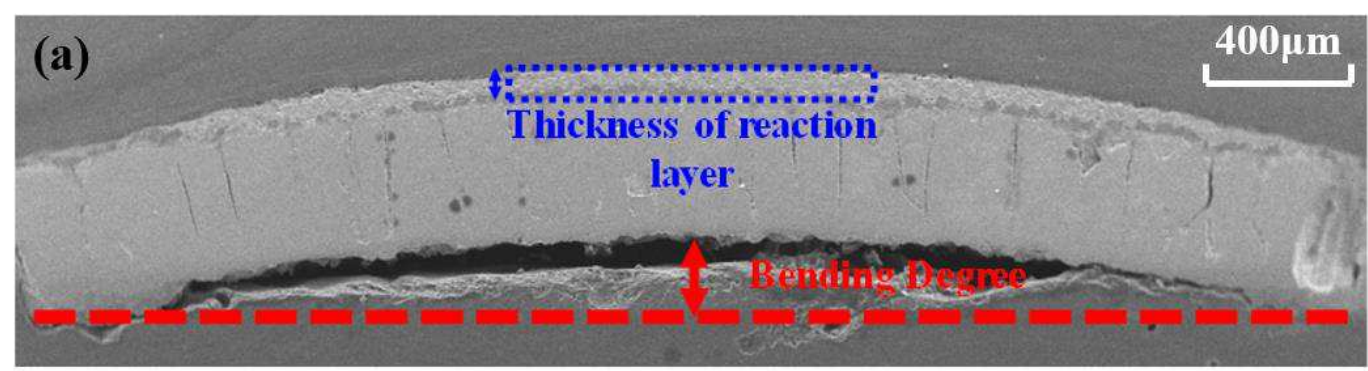

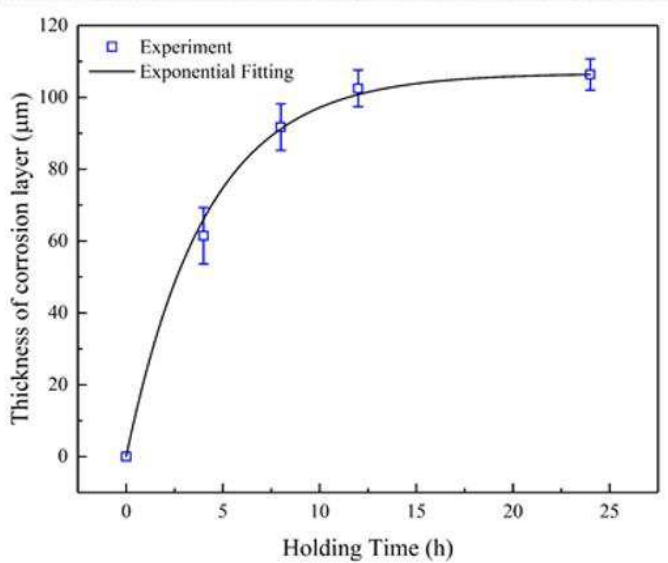

(b)

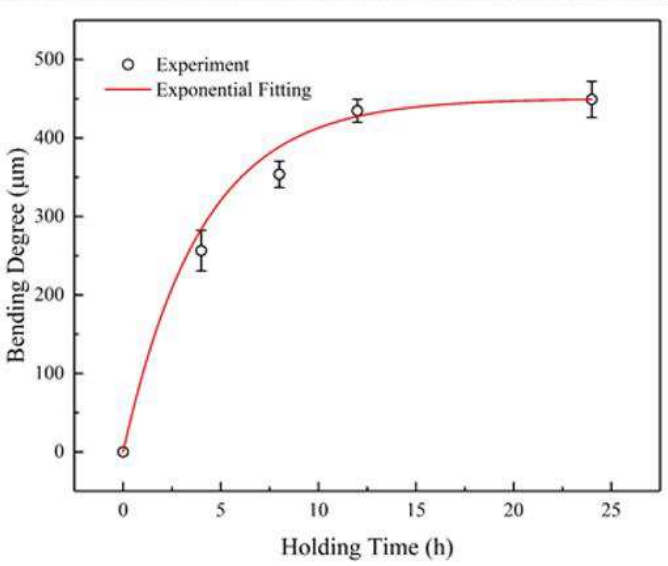

(c)

Fig. 3 (a) Defination of parameter and Functional image of (b) The reaction layer thickness and (c) bending degree of TBC as a function of holding time.

\section{Numerical modeling}

In this chapter, experimental analysis and numerical modeling are combined to 
study the temperature and stress fields of TBC (with BC and Sub) under CMAS attack. The method was described in the following. Firstly, a corrosion model of the CMAS attack is developed based on the experimental results. Next, a numerical simulation of the free-standing TBC is performed to determine the parameters for further simulation. Finally, a numerical model of a conventional TBC system (with BC and Sub) is constructed to oabtain temperature and stress fields during CMAS corrosion. All numerical simulations are performed with the software ABAQUS 6.14.

\subsection{Corrosion model under CMAS attack}

As shown in Fig. 4, the corrosion process is simplified. In the beginning, CMAS is located on the top of TBC as a thin layer. When temperatures is above the melting point of CMAS, molten CMAS reacts with the TBC and infiltrates into the pores or cracks. Subsequently, the reaction layer generates on the top of TBC and volume of the layer also expands. Therefore, CMAS corrosion process can be simplified as the generation and growth of the reaction layer, as well as the expansion of this layer. For precisely describing the processes, the reaction layer was devided into a number of small sections to simulate the increase of the reaction layer thickness in a short time interval. The transformation from the top coat to the reaction layer is considered as the change of material properties, which mainly includes Young's modulus, thermal conductivity, the cofficient of thermal expansion and poisson ratio. The difference in thermal expansion coefficients results in a thermal expansion mismatch between the layers during the cooling process. A volume expansion rate is also introduced to describe the reaction layer's expansion under CMAS attack, which is similar to the coefficient of corrosion expansion defined by Zhou et al. [26]. 

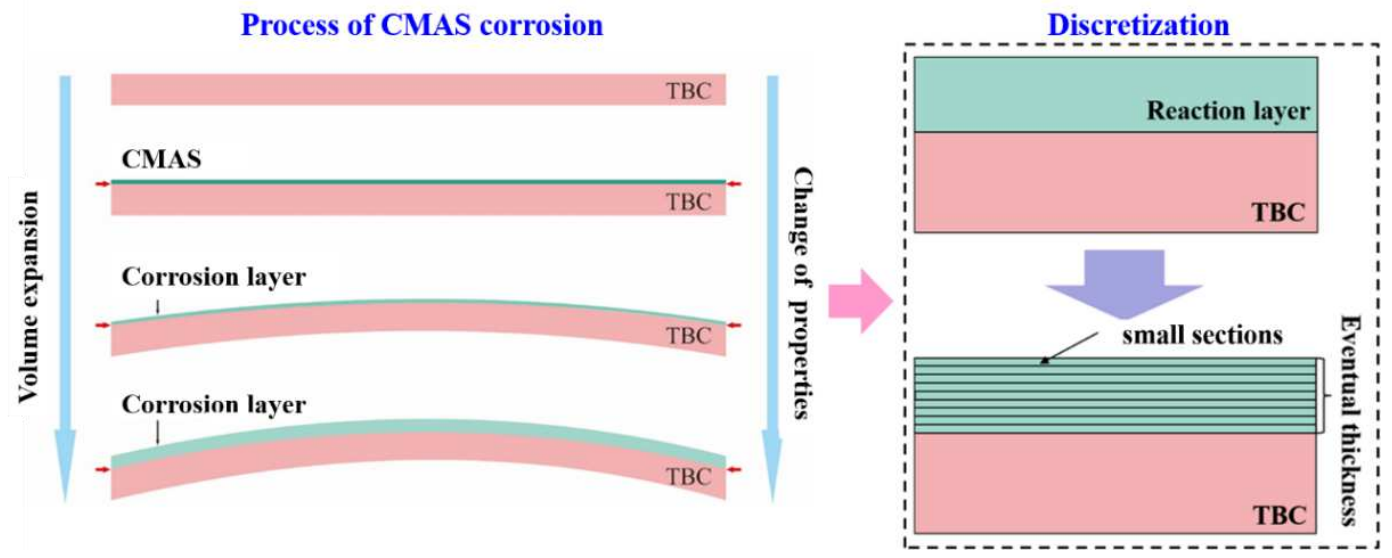

Fig. 4 Corrosion model of TBC for CMAS corrosion.

\subsection{Numerical model of free-standing TBC}

As shown in Fig. 5, a numerical model of free-standing TBC with multiple vertical cracks was established to simulate the deformation of TBC under CMAS attack. The loading conditions and boundary conditions are consistent with experimental conditions. A two-dimensional plane strain model is used here to simulate the corrosion process and fit the deformation of TBC in experiments. The formation of reaction layer due to the CMAS corrosion is simulated by USDFLD, and the expansion of reaction layer is simulated by UEXPAN, both of which are subroutines within ABAQUS. The length and thickness of the free-standing TBC model are set as $5 \mathrm{~mm}$ and $450 \mu \mathrm{m}$, respectively. The numbers and width of cracks are 20 and $5 \mu \mathrm{m}$, respectively. The constraint in $\mathrm{Y}$ direction is applied to two base angles of the model. Stress-free conditions are applied to other surfaces. Since the environment is uniform in a muffle furnace, a uniform temperature $\left(1400^{\circ} \mathrm{C}\right)$ is applied to the whole model with a heating rate of $5{ }^{\circ} \mathrm{C} / \mathrm{min}$.

Free-standing TBC were meshed with four-node bilinear plane strain quadrilateral reduced integration elements (CPE4R). Four materials were defined, i.e., YSZ, pore, CMAS, and reaction layer. All materials are considered as isotropic, homogeneous and linear elastic materials $[27,30,34,35,36]$. The material parameters are given in Table 1 .

The Young's modulus and the Poisson's ratio of the reaction layer are also obtained from numerical simulations. As shown in Fig. 2, CMAS is one of the major composition of the reaction layer. The composition of the YSZ after CMAS corrosion 
is consistent with as-sprayed coatings [33]. Therefore, the reaction layer is assumed as a mixture of three materials, i.e., YSZ, CMAS, and pores. The amount of pores of reaction layer increased under CMAS attack. As illustrated in Fig. 6, SEM images of the reaction layer were collected, and their feature information evaluated by OOF (Object-Oriented Finite elements), which used a plane strain model to calculate the Young modulus [37,38]. According to the calculation, the Poisson's ratio of the reaction layer is about 0.3 , and the Young's modulus is $142 \mathrm{GPa}$. The thermal expansion coefficient of reaction layer is $10.6 \times 10^{-6} \mathrm{~K}^{-1}[39]$.

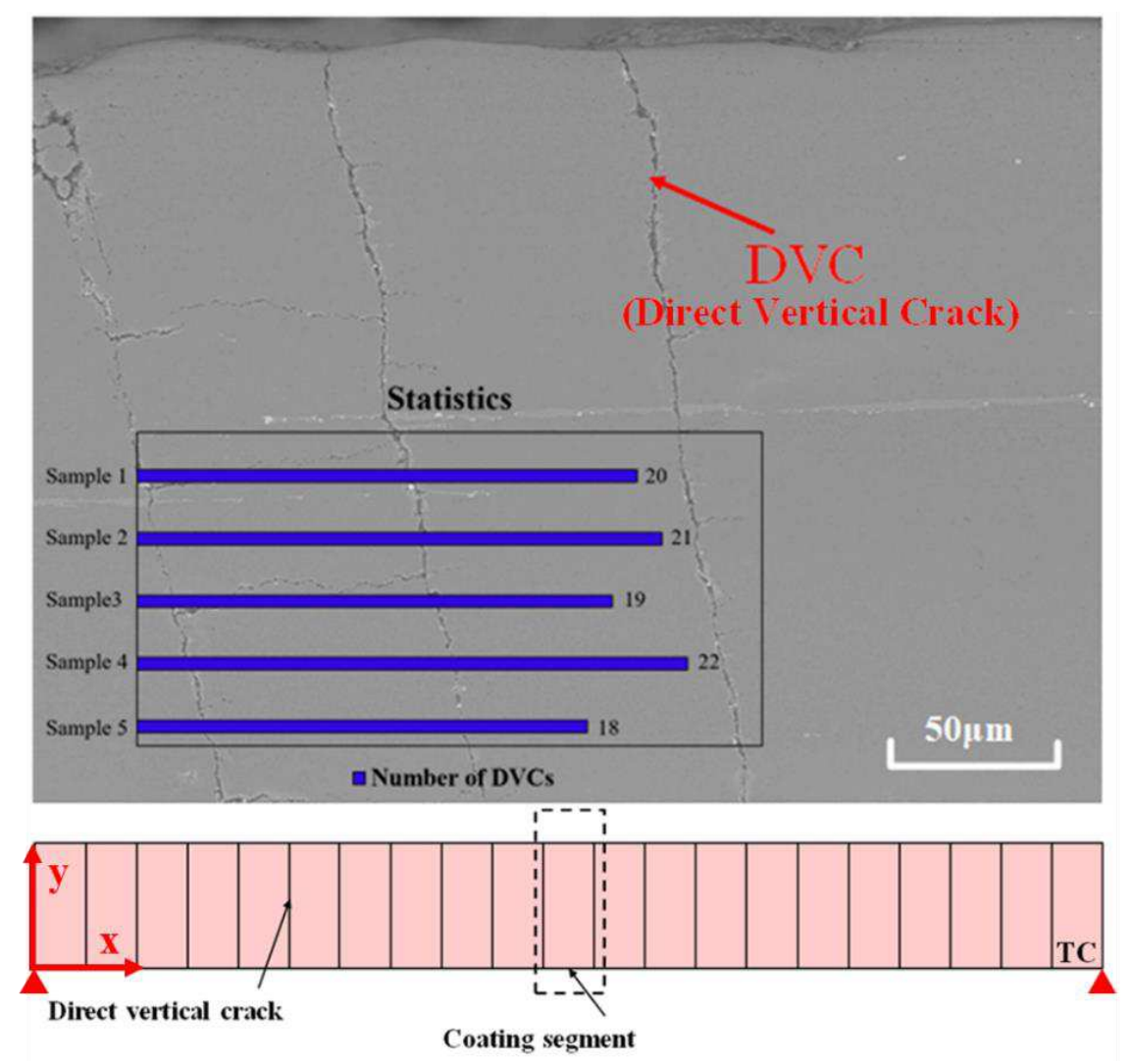

Fig. 5 Illustration of the geometry of free-standing TBC with direct vertical cracks before CMAS corrosion.

Table 1 The materials properties of free-standing TBC used in simulation

\begin{tabular}{ccccc}
\hline Material & Reaction layer & TC & Pore & CMAS \\
\hline Young modulus (Gpa) & 142 & 160 & 2 & 84 \\
Poisson's ratio & 0.3 & 0.3 & 0.3 & 0.3 \\
Thermal expansion coefficient $\left(\mathrm{K}^{-1}\right)$ & $10.6 \times 10^{-6}$ & $11 \times 10^{-6}$ & $11 \times 10^{-6}$ & $8.1 \times 10^{-6}$ \\
Thermal conductivity $\left(\mathrm{Wm}^{-1} \mathrm{~K}\right)$ & & 1.05 & 0.2 & 1.78 \\
\hline
\end{tabular}


(a)

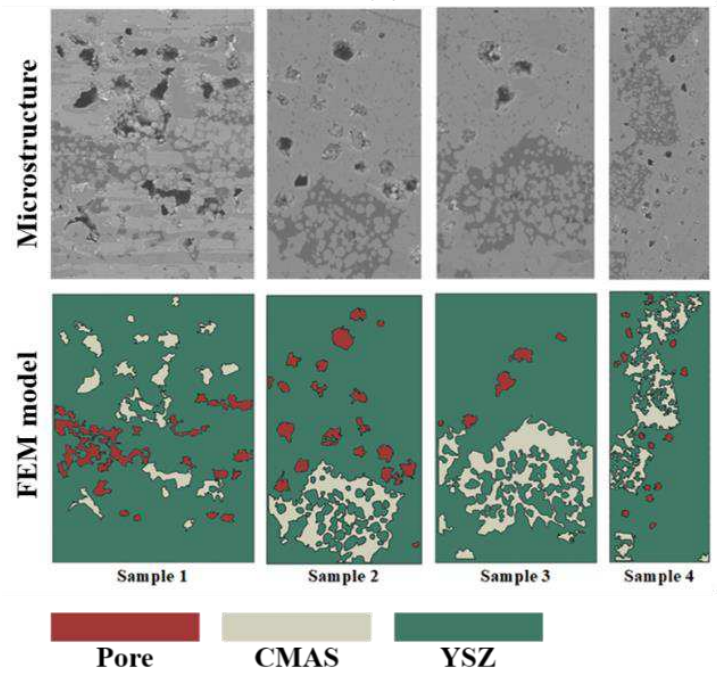

(b)

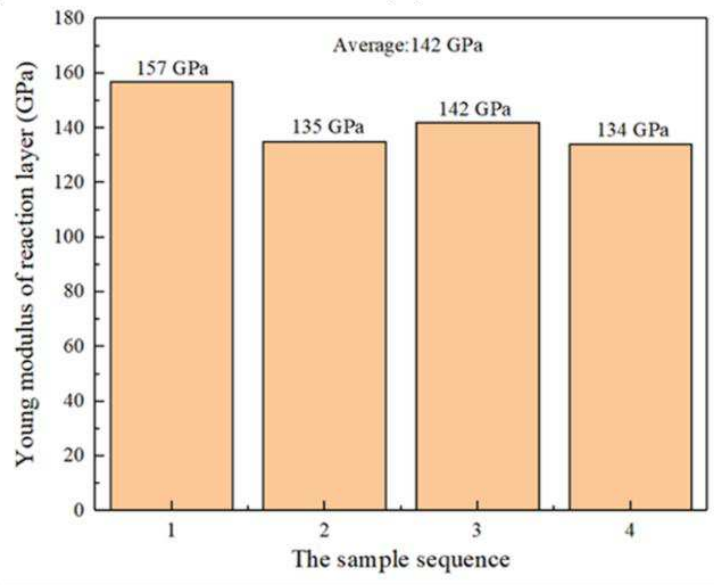

Fig. 6 (a) SEM investigation and phase evaluation of the reaction layer for the OOF analysis, (b) results of Young's modulus estimation by OOF.

\subsection{Volume expansion rate}

The volume expansion rate is a critical parameter that reflects the real-time volume strain of the reaction layer during CMAS corrosion. It is difficult to directly determine in experiments. However, the bending rate of TBC can be obtained by differentiating of Eq. (2). Assuming the expression of volume expansion rate is similar to the bending rate of $\mathrm{TBC}$ due to their physical correlation, the following expression for volume expansion rate can be obtained,

$$
V_{\text {expansion }}=A \cdot e^{\left(-\frac{T}{B}\right)}
$$

where the $V_{\text {expansin }}$ denotes the volume expansion rate; $\mathrm{A}$ and $\mathrm{B}$ are constants. The values of A and B were calculated by control variable method. Different A or B were used in this equation to fit the bending rate of $\mathrm{TBC}$ obtained from numerical simulation and experiments, respectively, as shown in Fig. 7. As a result, the most suitable values of A and $\mathrm{B}$ are given in Eq. (6).

$$
V_{\text {expansion }}=3.3 \cdot 10^{-5} \cdot e^{\left(-\frac{T}{10}\right)}
$$




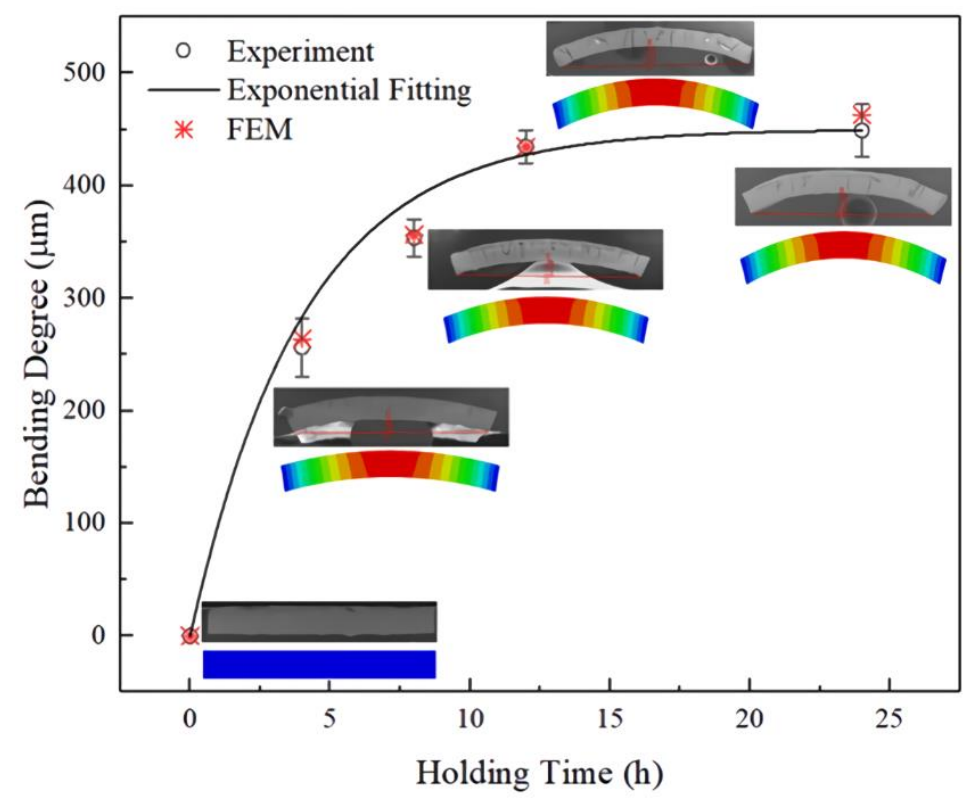

Fig. 7 Experimental and simulated results of bending degree with free-standing TBC model.

\subsection{Numerical model of the normal TBC}

As shown in Fig. 8, the normal TBC model includes three layers, i.e., TC, BC, and Sub. The material properties that controlling the corrosion process are consistent with these in the free-standing TBC model. It is assumed that the corrosion process only happened in holding time. The thickness of $\mathrm{BC}$ and Sub are $200 \mu \mathrm{m}$ and $3 \mathrm{~mm}$, respectively. The length of the considered segment is $115 \mu \mathrm{m}$, based on the SEM image size shown in Fig. 5. The symmetric boundary condition is applied to the left of the model and periodic boundary condition on the right. The constraint of Y direction is applied to two base angles of the model. Stress-free conditions are applied to other surfaces. It should be noted that the direct vertical cracks, which are too small to influence the temperature and stress fields, and the TGO formed during the service, are not considered in the simulations.

To be consistent with work conditions, thermal conduction is added to the normal TBC model. Therefore, the calculation adopted a coupled temp-displacement model, which is in steady state. As shown in Fig. 8, the different temperature boundary conditions are applied to the top surface and bottom surface. TC, BC, and substrate are meshed with four-node plane strain thermally coupled quadrilateral, bilinear 
displacement, and temperature elements, which are all considered as isotropic, homogeneous, and linear elastic materials. The material properties are given in Table 2 [27,30,34,35,36]. As shown in Fig. 9 , the thermal conductivity of reaction layer $(0.8836$ $\mathrm{Wm}^{-1 \circ} \mathrm{C}$ ) is calculated based on OOF method and the Fourier heat conduction equation $[37,38]$. The thermal conductivity becomes smaller when the material transforms from $\mathrm{TC}$ to reaction layer.

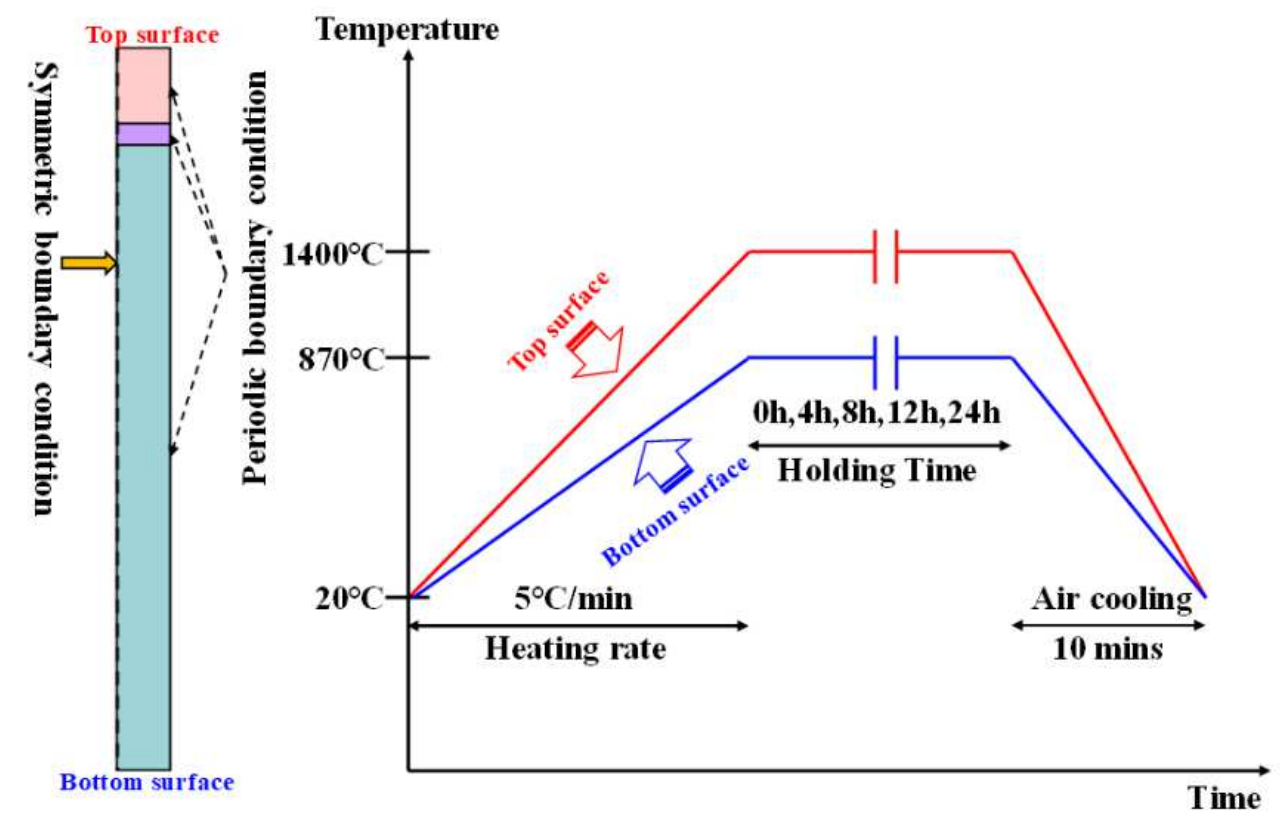

Fig. 8 Illustration of the geometry of TBC before CMAS corrosion and temperature loading of the TBC model.

(a)

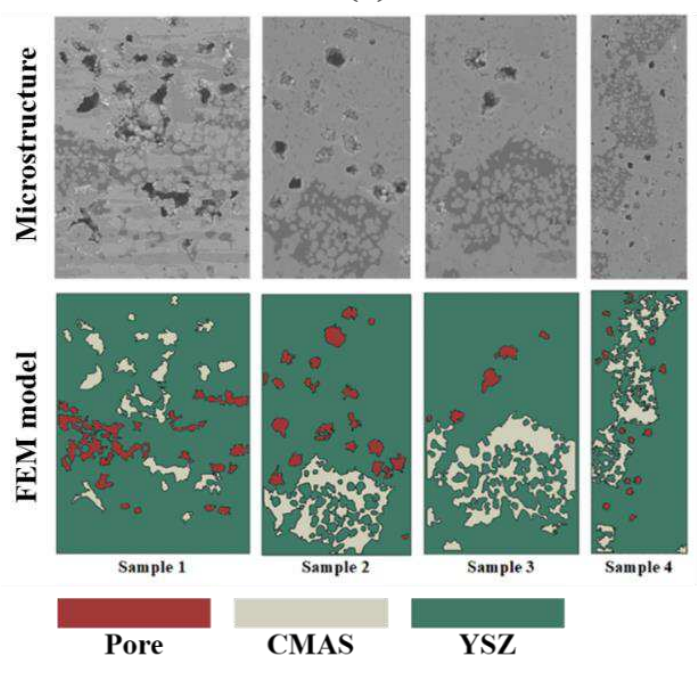

(b)

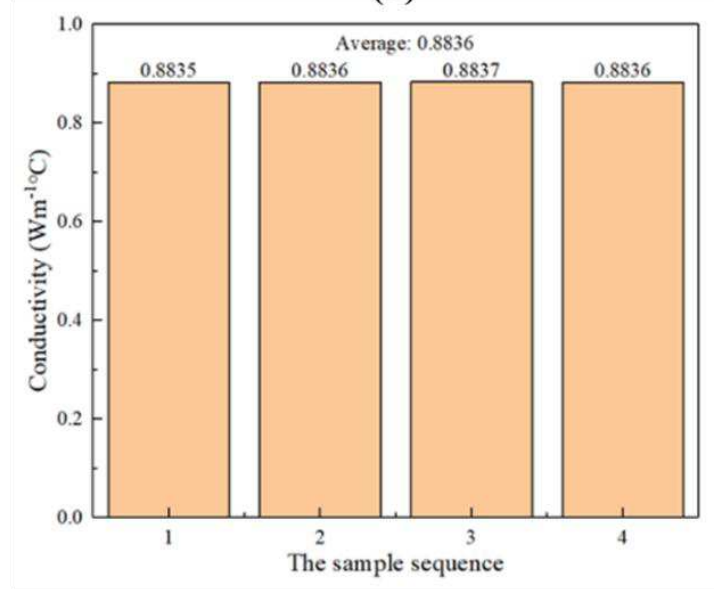

Fig. 9 Calculation of thermal conductivity for normal TBC. 
Table 2 The material properties of normal TBC used in simulation

\begin{tabular}{cccc} 
Material & Reaction layer & BC & Sub \\
\hline Young modulus (Gpa) & 142 & 180 & 200 \\
Poisson's ratio & 0.3 & 0.3 & 0.3 \\
Thermal expansion coefficient $\left(\mathrm{K}^{-1}\right)$ & $10.6 \times 10^{-6}$ & $16 \times 10^{-6}$ & $14 \times 10^{-6}$ \\
Thermal conductivity $\left(\mathrm{Wm}^{-1} \mathrm{~K}\right)$ & 0.8836 & 6.4 & 17.3 \\
\hline
\end{tabular}

\section{Numerical results and discussions}

A systematic exploration of the effects of CMAS corrosion on the temperature and stress fields is essential for a better understanding of the failure mechanisms of TBC in CMAS corrosion.

\subsection{Temperature field of TBC}

It is well-known that CMAS corrosion changes the material properties of $\mathrm{TBC}$, such as thermal conductivity; as a result, the steady temperature field of TBC should be changed in CMAS corrosion. In this section, as shown in Fig. 10, five different group of silulations were performed with different conditions to discusses the steady temperature field effected by CMAS corrosion, in which holding time is set as $0,4,8$, 12 and $24 \mathrm{~h}$, respectively.

The temperature field of TBC during CMAS corrosion is illustrated in Fig. 10(a), in which temperature gradient along the thickness direction of TBC is clearly observed. As holding time increased, there are no obvious changes in the temperature field of $\mathrm{TBC}$, but the zone of low temperature is increasing slightly. Obviously, the change is relevant to the thermal conductivity of the material system, which is effected by CMAS corrosion.

As shown in Fig.10(b), the contour map of top layer is enlarged to further explore the influence of CMAS corrosion on the temperature field. Firstly, the temperature of corrosion layer is above $1400{ }^{\circ} \mathrm{C}$, which confirms that CMAS is molten in the zone so that normally reacts with YSZ. Secondly, top layer exhibits high ability of thermal insulation. The zone has complex distribution of temperature, which exists great 
temperature gradients from top to bottom of TC layer (decreasing from 1250 to $1000^{\circ} \mathrm{C}$ ). And the area at the highest temperature in the corrosion zone decrease within holding time, which confirms that the thermal conductivity decrease in the zone.

Path-1, which is figured out by red arrow along the thickness direction in Fig. 10(c), is selected to calculate the specific temperature distribution of TBC. The line chart includes five overlapped lines representing five different holding time, which confirms that CMAS corrosion has a slight influence on the temperature disribution. Furthermore, it confirms that CMAS corrosion has little influence on thermal stress due to the small difference in thermal expansion coefficient of TC and reaction layer, at least in this work.

Generally speaking, CMAS corrosion decreases the thermal conductivity of the material in corrosion zone, so that the ability of thermal insulation improves relevantly. However, the thermal conductivity decrease or thermal insulation improvement is too small to affect the temperature distribution. In addition, thermal stress is directly relevant to temperature distribution, so that the thermal stress is not the main factor caused the failure in CMAS corrosion at elevated temperature.

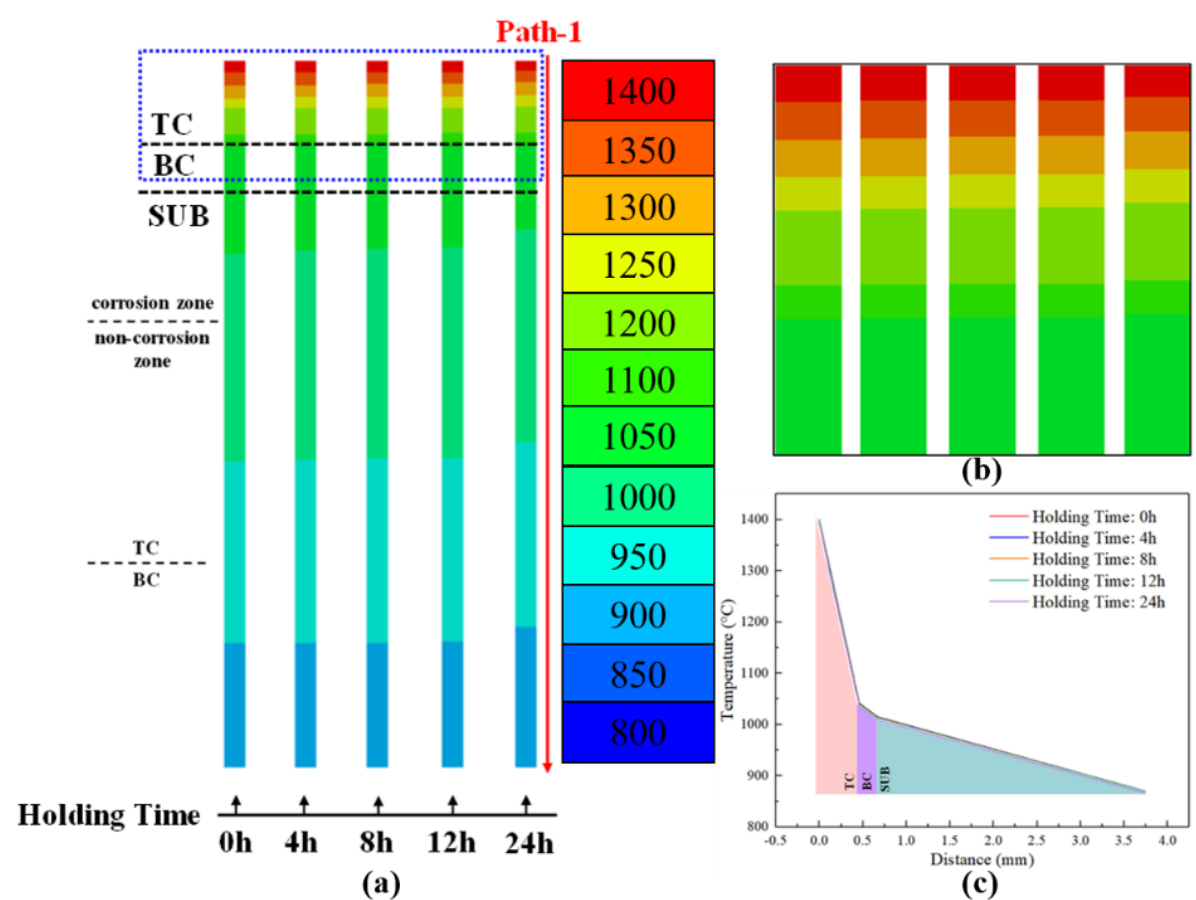

Fig. 10 Distribution of temperature fields of TBC during CMAS corrosion. 


\subsection{Stress field of TBC}

It is of great importance to study the the stress field since it reflects the root cause of TBC failure. In this section, the distribution and evolution of stress fields in TBC during CMAS corrosion, taking $24 \mathrm{~h}$ (holding time) as an example, are detailed discussed. As shown in Fig. 11, stress contour reflects the distribution and evolution of Mises stress and the principal stress along x-direction in TBC are plotted, respectively. Seven sets of contour maps, which represent different time during CMAS corrosion, are given to discuss the stress distribution and evolution of TBC.

Mises stress is suitable for estimating the degree of damage as an evaluation criterion. As shown in the stress contour map of Mises stress, in Fig. 11(a), $\mathrm{TBC}$ is zero stress in the original state. Heating makes stress layered in TC and BC, which is the attribute to different coefficient of thermal expansion of two layers, as shown in Fig. 11(b), but it is on the same order of magnitude. In the next four pictures, it is obvious that the region of high stress generates at the top of $\mathrm{TBC}$, and the zone becomes larger gradually over holding time. TBC generates obvious volume strain due to CMAS infiltrates the cracks or micro-pores, which leads to an increase in stress. It should be noted that the gradient of stress generated in the zone, which reflects the additive effect of stress. In the beginning, CMAS is a thin layer coated on the TBC. And it reacts with TBC in different thickness, which leads to volume expansion of the layer. The expansion generates tensile stress within the layer, and it suffers compressive stress from the next layer. The next layer suffers tensile stress from the expansion layer and becomes a new expansion layer over time, so that it generates additive stress compared with the last layer. It is obvious that the most significant stress occurs at the bottom of the corrosion zone. Obviously, the stress in corrosion zone is an order of magnitude higher than other zone, which indicates that the corrosion zone is the high-risk area.

S11 stress means the principal stress along 1 direction or $\mathrm{x}$ direction. It is obvious that TBC suffers compressive stress under corrosion due to boundary conditions. As an independent columnar structure of TBC, the model must suffer squeezing from other columnar structures, so that compressive stress is dominated component. The evolution 
trend of stress is similar to Mises stress, which shows obvious stress gradient along with the thickness direction of TBC, and the biggest compressive stress occurs at the bottom of the corrosion zone. The generation of the biggest compressive stress is the additive effect of strain, which is keeping the same with experimental results. It should be noted that the cooling stage is the crucial stage in traditional thermal experiments. However, there is no obvious distinction of the stress field in the holding stage and cooling stage, which indicates that thermal stress is not dominated factor compared with other volume strain during CMAS corrosion.

In general, the contour maps indicate that the corrosion zone generates an obvious higher stress state than other zone, and the interface of TC and BC also exists an obvious distinction of stress. The high stress state of corrosion zone and misfit stress of interface (TC and BC) during CMAS corrosion are possible to cause the failure of TBC. Therefore, path-1 in Fig. 10, path-2 (along the thickness direction) and path-3 (along the width direction and stay in the interface) in Fig. 11 are selected to further study the stress field of two crucial locations, as shown in Fig. 12.

As shown in Fig. 12(a), it is obvious that the corrosion zone generates stress mutation, and stress state in the zone is higher than other zones. The location of the peak of stress is moving down along thickness direction, since CMAS infiltrates deeper over time. The figure in the dashed box exhibits the stress evolution of the corrosion zone more clearly. The evolution of stress field is studied over time in the whole process. Stress generates in the heating stage due to thermal expansion, and decreases along the thickness direction. CMAS corrosion leads to the generation of stress mutation since it increases the volume strain of TBC. It is obvious that the peak of stress occurs in the location of CMAS infiltration, and the location of the peak moves down with the location of CMAS. The location of TBC infiltrated by CMAS stays high-stress state continuously. It will cause the rupture of TBC when the stress is big enough. In the specific holding time, the magnitude of stress in TBC exhibits parabolas in the corrosion zone, which shows the gradient of stress is linear along the thickness direction. The conclusion provides a forecast for the stress along the thickness direction and 
failure of TBC. For a specific thickness of TBC, the stress is increasing over time only in the heating stage and CMAS corrosion stage. In the cooling stage, the stress evolves from a high-stress state to a low-stress state. This variation will increase residual stress in TBC and decrease the lifetime of TBC.

The distribution and evolution of stress in the interface of $\mathrm{TC}$ and $\mathrm{BC}$ are illustrated in Fig. 12(b). The heating stage causes the stress state mutation in the interface, which transforms stress from low-stress state to high-stress state. It is obvious that CMAS corrosion has little influence on the stress state, which could be explained by the Saint-Venant principle. The transformation of stress in cooling stage is contrary to that in heating stage, and the high-low transformation of stress increases the risk of damage of TBC.

The numerical analysis indicates that CMAS corrosion has serious influences on stress field of TBC but quite limited influence on steady state temperature field. CMAS infiltration generates a high-stress region of the corrosion zone; and there is a parabolic relationship between the stress and thickness of TBC in specific holding time. The correlation of stress and thickness makes the stress predictable, which further increases the possibility for forecasting of TBC's lifetime during CMAS corrosion. The peak stress is possible to result in the increasing risk of rupture of $\mathrm{TBC}$ over holding time. However, CMAS corrosion has slight influence on the stress state of the interface (TC and BC), which is mainly affected by thermal stress. In general, the thickness of the infiltration of CMAS generates the most serious damage of TBC, which leads to the stress sharp increase and further increases the risk of damage. All these coclusions could provide effective advice for the protection of TBC in CMAS environment. 
(a)

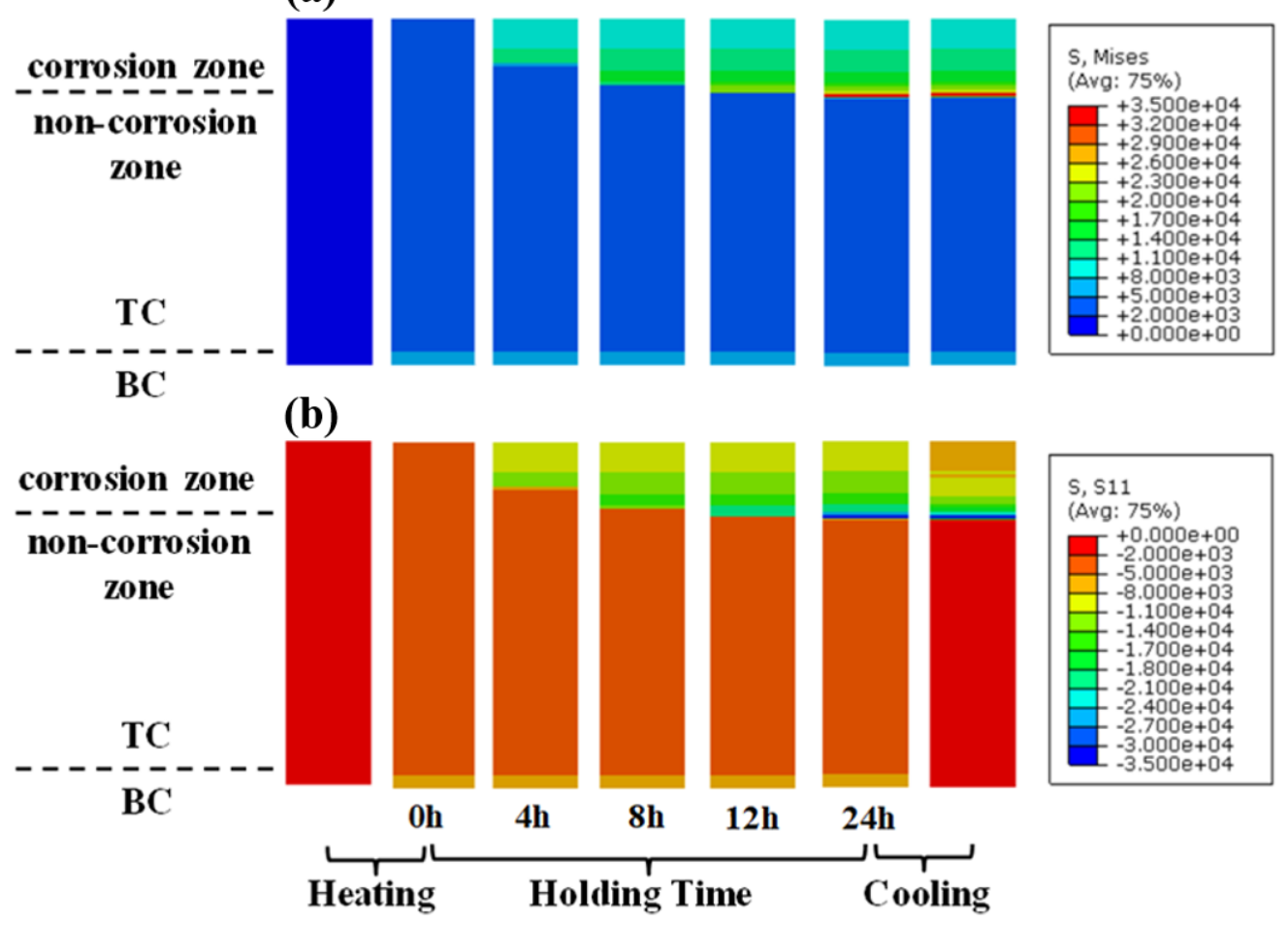

Fig. 11 Two kinds of stress contour plots in different stages (a) Mises stress and (b) The principal stress at $\mathrm{x}$ direction

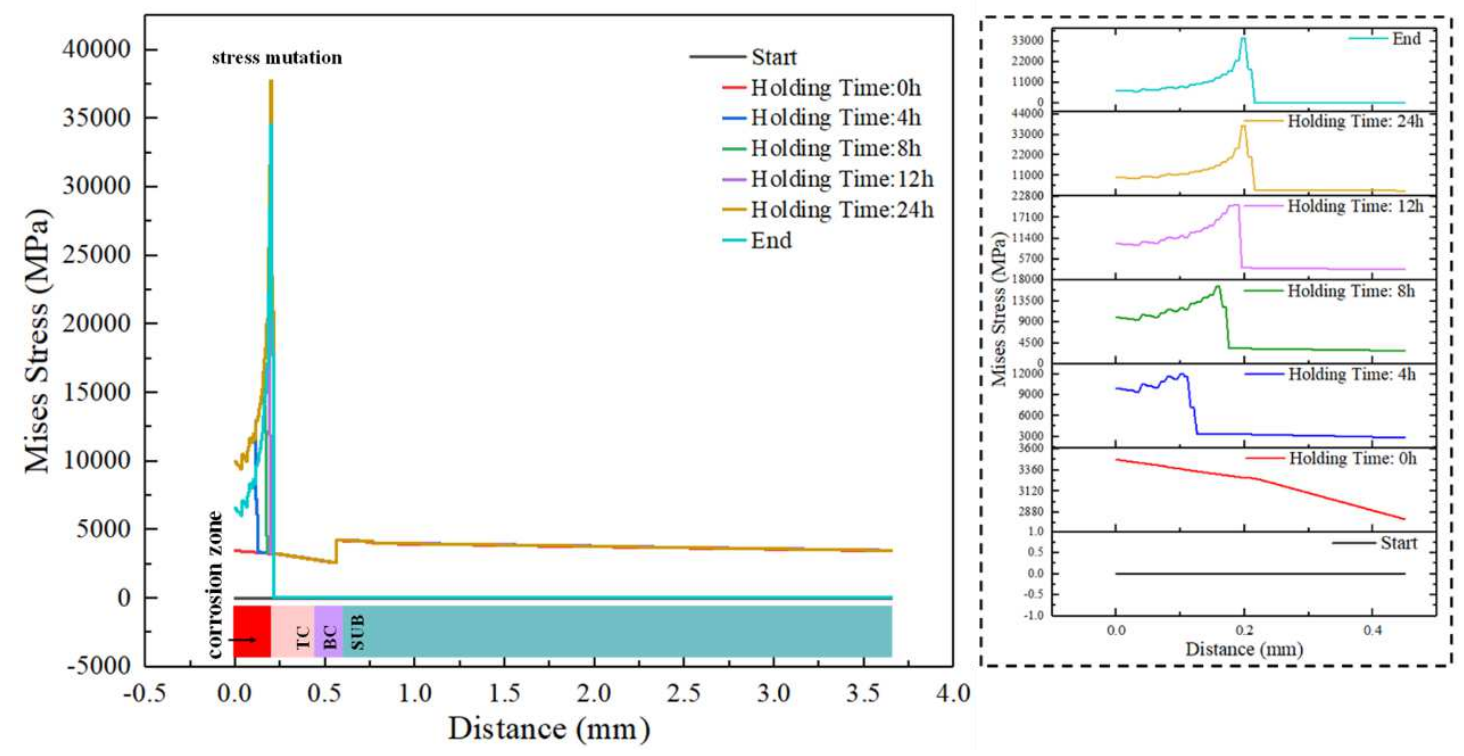

(a) 


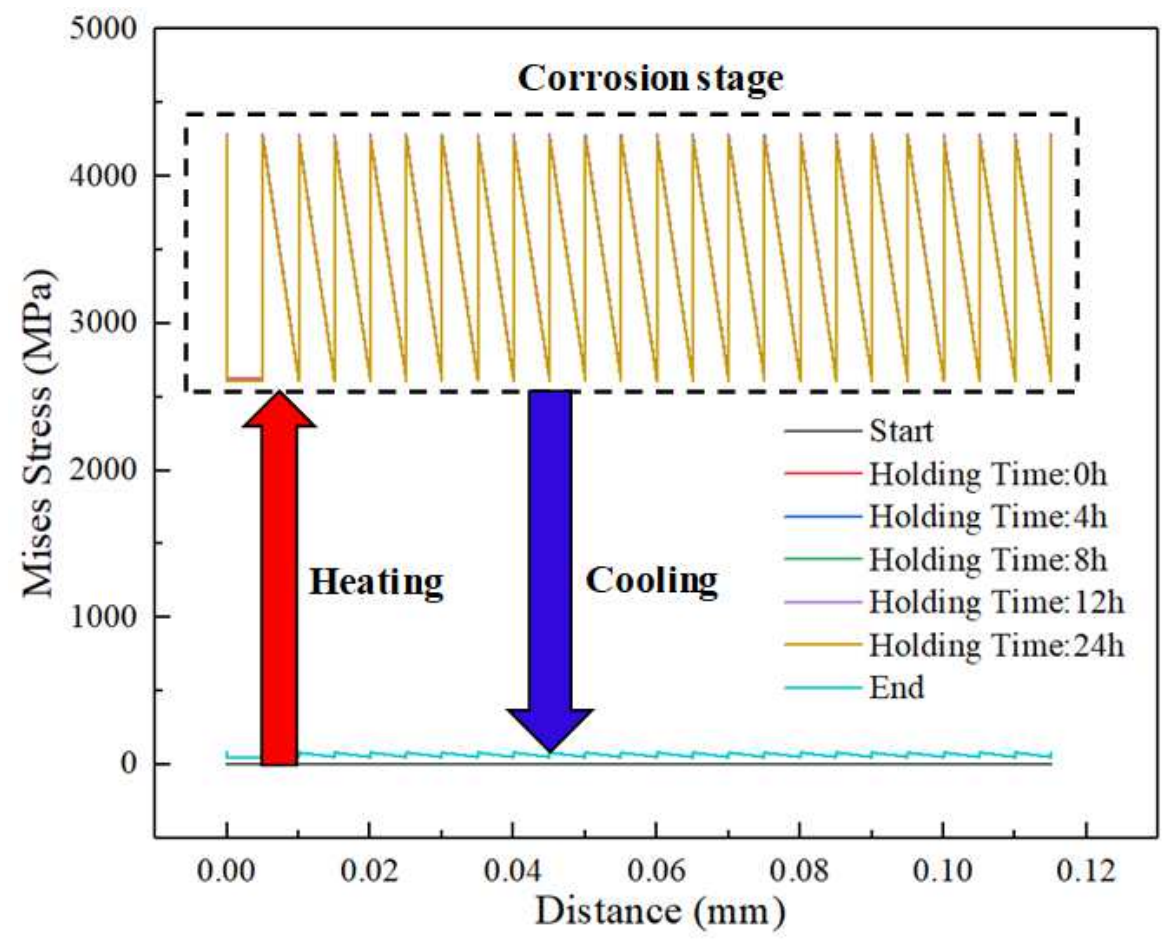

(b)

Fig. 12 (a) Stress distribution along path-1(in Fig. 11) and path-2(in Fig. 12, dashed box) in different corrosion stages and (b) stress distribution along path-3 (Fig. 12) in different corrosion stages.

\section{Conclusion}

In this work, the temperature and stress fields of SPS TBC during CMAS corrosion are investigated by combining experiments with numerical calculation. The results provide suggestions for decreasing the detriments of TBC in CMAS corrosion. The main conclusions are summarized as follows.

(1) The reaction between CMAS and YSZ is divided into three steps, i.e., dissolution, upon saturation and re-precipitation, respectively, which is accompanied by volume expansion since CMAS separated the grain boundaries of YSZ. The reaction layer thickness and bending degree exhibited a single exponential relationship with time.

(2) A corrosion model of CMAS is established. The corrosion process is simplified as follows, generation of the reaction layer, expansion of volume in the reaction zone, and increase of the reaction layer thickness. The relationship of volume expansion rate and time is monoexponential during CMAS corrosion. The numerical results are in good agreement with experiments. 
(3) The numerical results proved that CMAS corrosion has no obvious effect on steady temperature field, but has significant effect on the stress field of TBC. There is a parabolic relationship between the stress and thickness of $\mathrm{TBC}$ in the specific holding time. It should be noted that the peak of stress, which increases over holding time during CMAS corrosion, is one of the factors to induce brittle rupture of TBC. The interfacial stress has no obvious relationship with CMAS corrosion but the temperature.

(4) It is deduced that the volume strain generates the most serious damage in TBC, which is the main reason leading to stress mutation and concentration during CMAS corrosion. Therefore, restrain the volume strain of TBC or thickness of infiltration will decrease the detriments of CMAS corrosion.

\section{Acknowledgement}

This work is supported by the National Natural Science Foundation of China [1171101165] and [11902240]. 


\section{References}

[1] Li F, Zhou L, Liu J. et al. High-entropy pyrochlores with low thermal conductivity for thermal barrier coating materials. J Adv Ceram 2019, 8(4): 576-582.

[2] Chen L, Yang G-J. Epitaxial growth and cracking of highly tough 7YSZ splats by thermal spray technology. J Adv Ceram 2018, 7: 17-29.

[3] Jiang P, Fan XL, Sun YL, Li DJ, Wang TJ, Bending-driven failure mechanism and modelling of double-ceramic-layer thermal barrier coating system.Int J Solids Struct 2018, 130-131: 11-20.

[4] Sun F, Fan XL, Zhang T, et al. Numerical analysis of the influence of pore microstructure on thermal conductivity and Young's modulus of thermal barrier coating. Ceram Int 2020, 46: 24326-24332.

[5] Gleeson B. Thermal barrier coatings for aeroengine applications. J Propul Power 2006, 22: 375-383.

[6] Evans AG, Mumm DR, Hutchinson JW,et al. Mechanisms controlling the durability of thermal barrier coatings. Prog Mater Sci 2001, 46: 505-553.

[7] Sampath S, Schulz U, Jarligo MO, et al. Processing science of advanced thermalbarrier systems. MRS Bull 2012, 37: 903-910.

[8] Bernard B, Bianchi L, Malie A, et al. Columnar suspension plasma sprayed coating microstructural control for thermal barrier coating application. J Eur Ceram Soc 2016, 36: 1081-1089.

[9] Shahid M, Abbas M. Investigation of failure mechanism of thermal barrier coatings (TBC) deposited by EB-PVD technique. J Phys: Conf Ser 2013: 012021 (7 pp.)--012021 (7 pp.).

[10] Jiang P, Fan XL, Sun YL, et al. Competition mechanism of interfacial cracks in thermal barrier coating system. Mater Des 2017, 132: 559-566.

[11] Lima RS, Guerreiro BM, Aghasibeig M. Microstructural Characterization and Room-Temperature Erosion Behavior of As-Deposited SPS, EB-PVD and APS YSZ-Based TBC. J Therm Spray Technol 2019, 28: 223-232.

[12] Kueppers U, Cimarelli C, Hess KU, et al. The thermal stability of Eyjafjallajökull ash versus turbine ingestion test sands. J Appl Volcanol 2014, 3: 4.

[13] Levi CG, Hutchinson JW, Vidal-Sétif MH, et al. Environmental degradation of thermal-barrier coatings by molten deposits. MRS Bull 2012, 37: 932-941.

[14] Darolia R. Thermal barrier coatings technology: critical review, progress update, remaining challenges and prospects. Int Mater Rev 2013, 58: 315-348.

[15] Li L, Hitchman N, Knapp J. Failure of thermal barrier coatings subjected to CMAS attack. J Therm Spray Technol 2010, 19: 148-155.

[16] Nicholls JR, Deakin MJ, Rickerby DS. A comparison between the erosion behaviour of thermal spray and electron beam physical vapour deposition thermal barrier coatings. Wear 1999, 233: 352-361.

[17] Wellman RG, Deakin MJ, Nicholls JR. The effect of TBC morphology on the erosion rate of EB PVD TBC. Wear 2005, 258: 349-356.

[18] Chen X, He MY, Spitsberg I, Fleck NA, et al. Mechanisms governing the high temperature erosion of thermal barrier coatings. Wear 2004, 256: 735-746.

[19] Evans AG, Fleck NA, Faulhaber S, et al. Scaling laws governing the erosion and impact resistance of thermal barrier coatings. Wear 2006, 260: 886-894.

[20] Stott FH, DeWet DJ, Taylor R. Degradation of thermal-barrier coatings at very high temperatures. MRS Bull 1994, 19: 46-49.

[21] Craig M, Ndamka NL, Wellman RG, et al. Technology C, CMAS degradation of EB-PVD TBC: the effect of basicity. Surf Coat Technol 2015, 270: 145-153. 
[22] Wu J, Guo HB, Gao YZ, et al. Microstructure and thermo-physical properties of yttria stabilized zirconia coatings with CMAS deposits. J Eur Ceram Soc 2011, 31 : 1881-1888.

[23] Garces HF, Senturk BS, Padture NP. In situ Raman spectroscopy studies of hightemperature degradation of thermal barrier coatings by molten silicate deposits. Scr Mater 2014, 76: 29-32.

[24] Xu GN, Yang L, Zhou YC, et al. A chemo-thermo-mechanically constitutive theory for thermal barrier coatings under CMAS infiltration and corrosion. J Mech Phys Solids 2019, 133: 103710.

[25] Shan X, Zou Z, Gu L, et al. Buckling failure in air-plasma sprayed thermal barrier coatings induced by molten silicate attack. Scr Mater 2016, 113: 71-74.

[26] Krämer S, Faulhaber S, Chambers M, et al. Mechanisms of cracking and delamination within thick thermal barrier systems in aero-engines subject to calcium-magnesium-alumino-silicate (CMAS) penetration. Mater Sci Eng A 2008, 490: 26-35.

[27]Chen X. Calcium-magnesium-alumina-silicate (CMAS) delamination mechanisms in EB-PVD thermal barrier coatings. Surf Coat Technol 2006, 200: 3418-3427.

[28] Nusier SQ, Newaz GM. Transient residual stresses in thermal barrier coatings: analytical and numerical results. J Appl Mech 1998: 346-353.

[29] Chuang TJ, Fuller ER. Analysis of Residual stress state in thermal barrier coatings. Fract Mech Ceram 2002: 169-178.

[30] Kyaw S, Jones A, Hyde T. Predicting failure within TBC system: Finite element simulation of stress within TBC system as affected by sintering of APS TBC, geometry of substrate and creep of TGO. Eng Fail Anal 2013, 27: 150-164.

[31] Krämer S, Yang J, Levi CG, et al. Thermochemical interaction of thermal barrier coatings with molten $\mathrm{CaO}-\mathrm{MgO}-\mathrm{Al} 2 \mathrm{O} 3-\mathrm{SiO} 2$ (CMAS) deposits. J Am Ceram Soc 2006, 89: 3167-3175.

[32] DeWet DJ, TaylorR, Stott FH. Corrosion mechanisms of ZrO2-Y2O3 thermalbarriercoatings in the presence of molten middle-east sand. J Phys IV Colloque 3 (C9) 1993: 655-663.

[33] Wu YY, Luo H, Cai CY, et al. Comparison of CMAS corrosion and sintering induced microstructural characteristics of APS thermal barrier coatings, J Mater Sci Technol 2019, 35: 440-447.

[34] Ranjbar-Far M, Absi J, Mariaux G, et al. Crack propagation modeling on the interfaces of thermal barrier coating system with different thickness of the oxide layer and different interface morphologies. Mater Des 2011, 32: 4961-4969.

[35] Kakuda TR, Levi CG, Bennett TD. The thermal behavior of CMAS-infiltrated thermal barrier coatings. Surf Coat Technol 2015, 272: 350-356.

[36] Wiesner VL, Bansal NP. Mechanical and thermal properties of calciummagnesium aluminosilicate (CMAS) glass. J Eur Ceram Soc, 2015, 35: 2907-2914.

[37] Langer SA, Fuller ER, Carter WC. OOF: an image-based finite-element analysis of material microstructures. Comput Sci Eng 2001, 3: 15-23.

[38] Gupta M, Curry N, Nylén P, et al. Design of next generation thermal barrier coatings - experiments and modelling. Surf Coat Technol, 2013, 220: 20-26.

[39] Interaction of molten silicates with thermal barrier coatings under temperature gradients. Acta Mater 2015, 89: 396-407. 


\section{Figures}

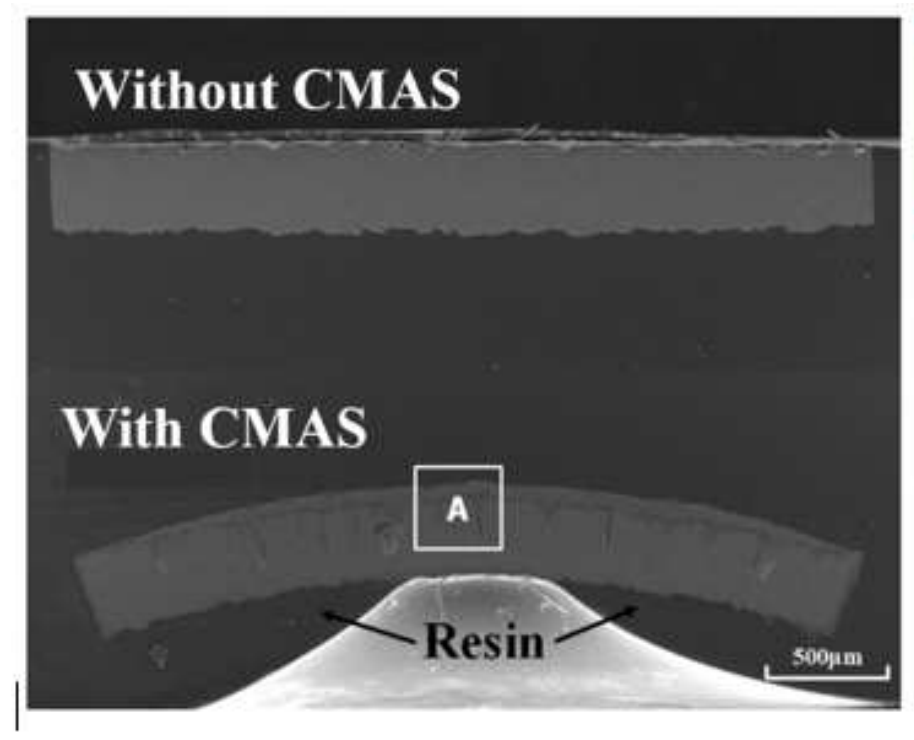

(a)

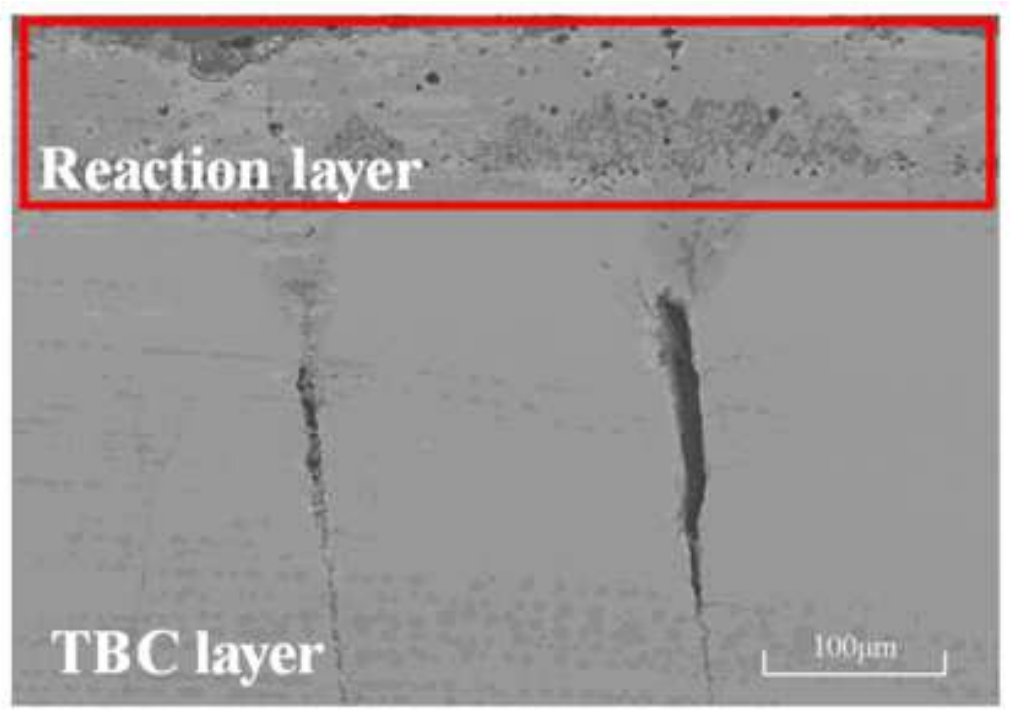

(b)

\section{Figure 1}
a) Cross-sectional images of the TBC after heat treatment at $1250^{\circ} \mathrm{C}$ for $8 \mathrm{~h}$ without and with CMAS, and (b) micromorphology with higher resolution of area $\mathrm{A}$. 

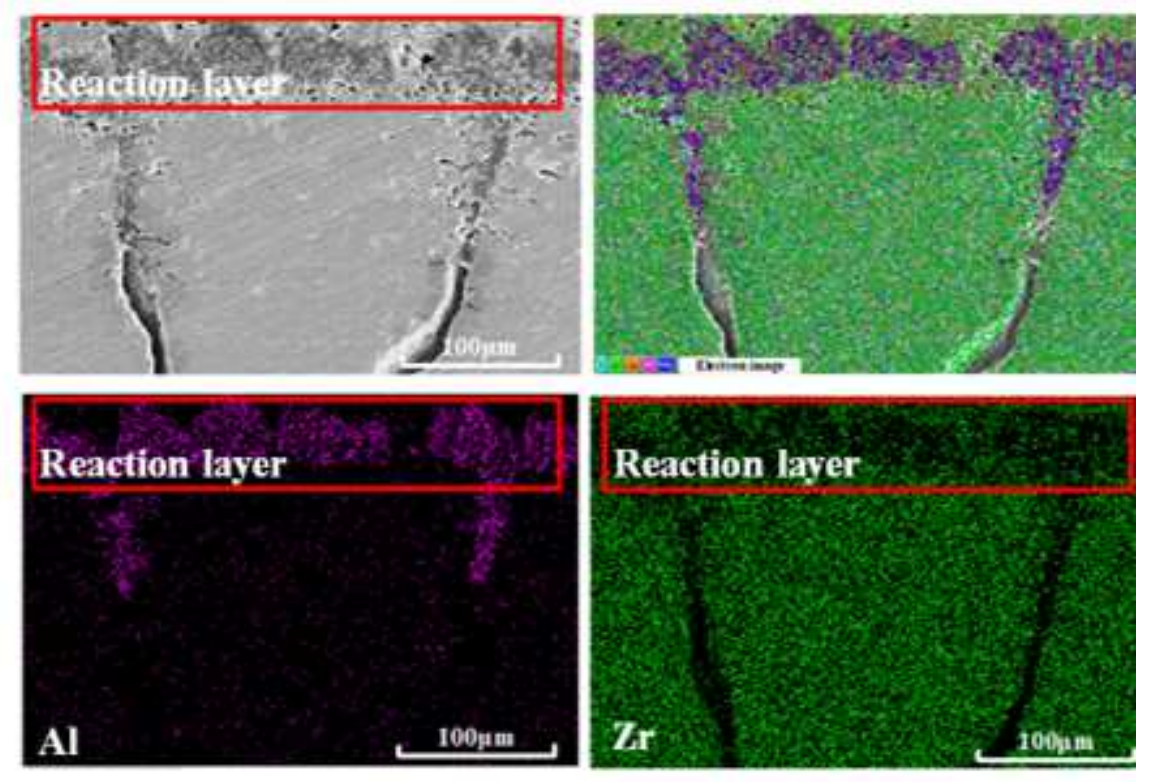

(a)
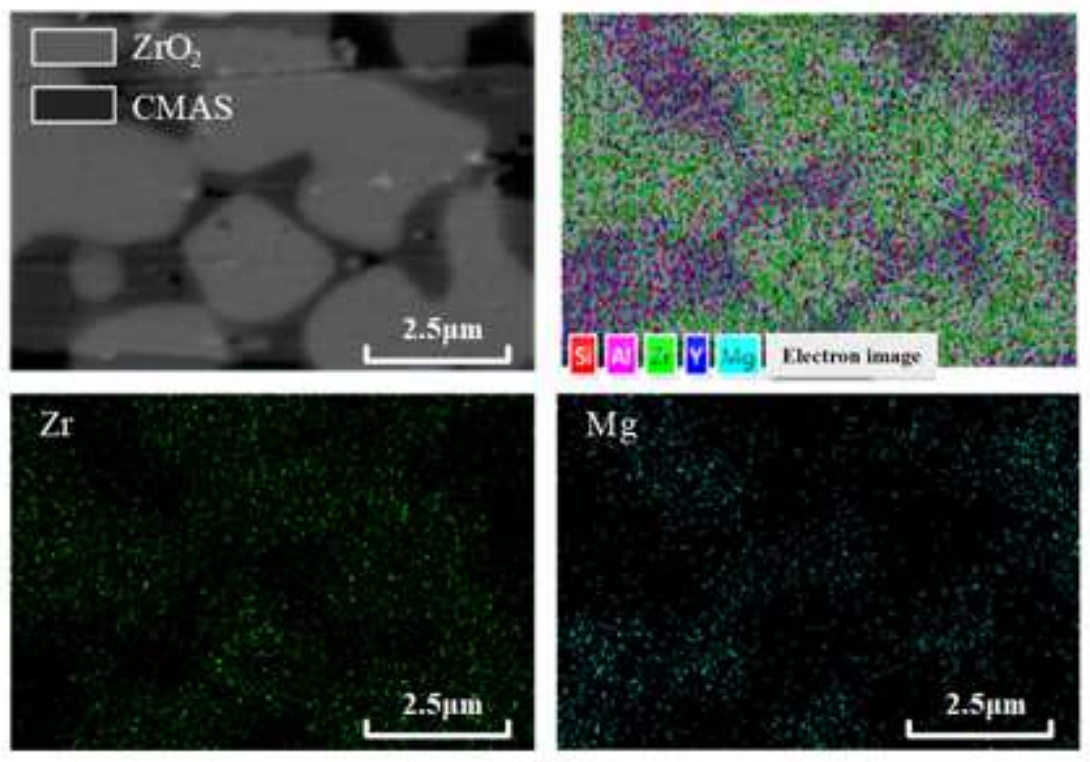

(b)

\section{Figure 2}

EDS images of (a) TBC and (b) reaction layer after heat treatment at $1250^{\circ} \mathrm{C}$ for $12 \mathrm{~h}$ with CMAS. 


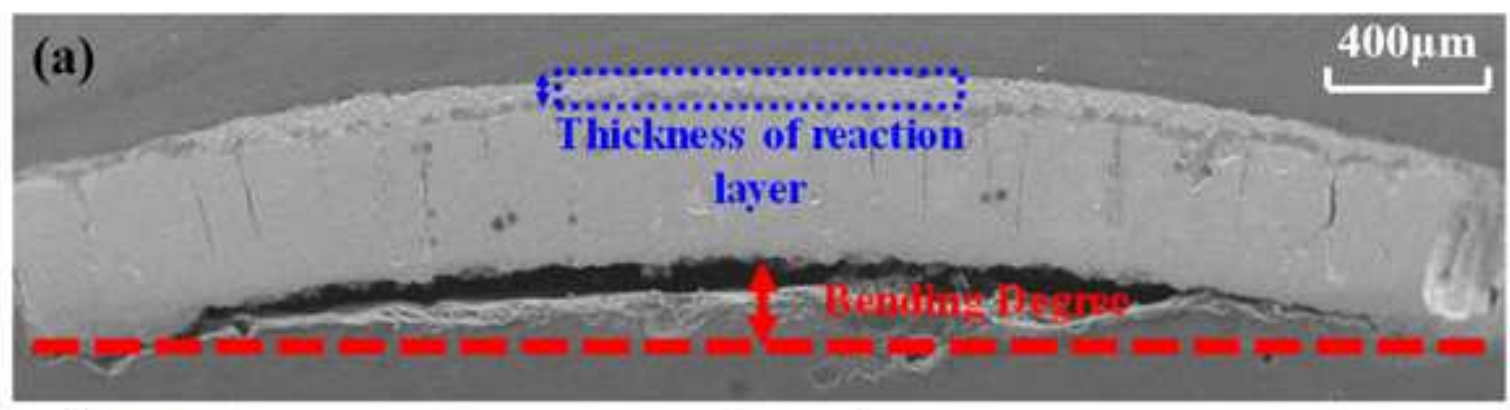

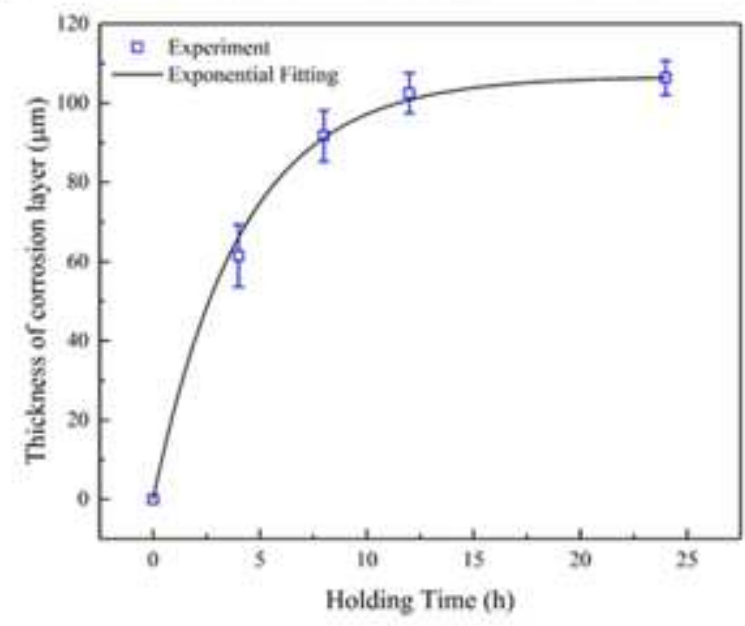

(b)

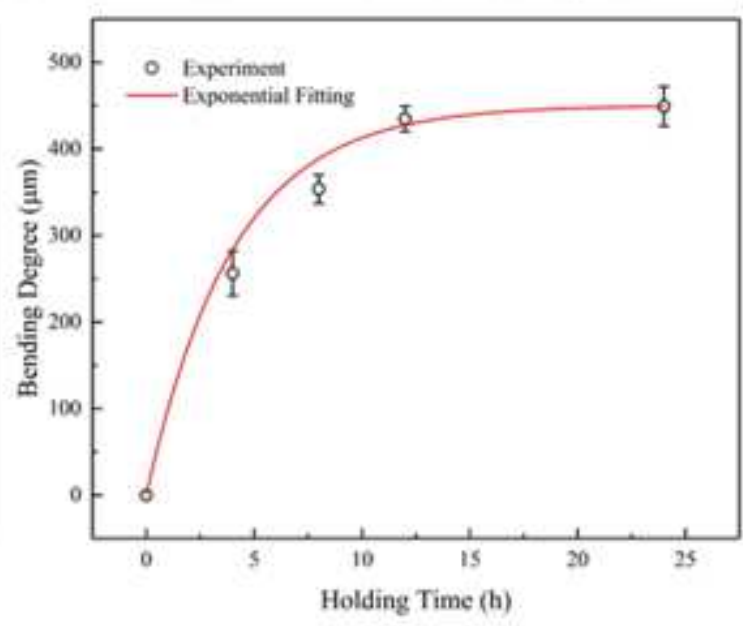

(c)

\section{Figure 3}

(a) Defination of parameter and Functional image of (b) The reaction layer thickness and (c) bending degree of TBC as a function of holding time.
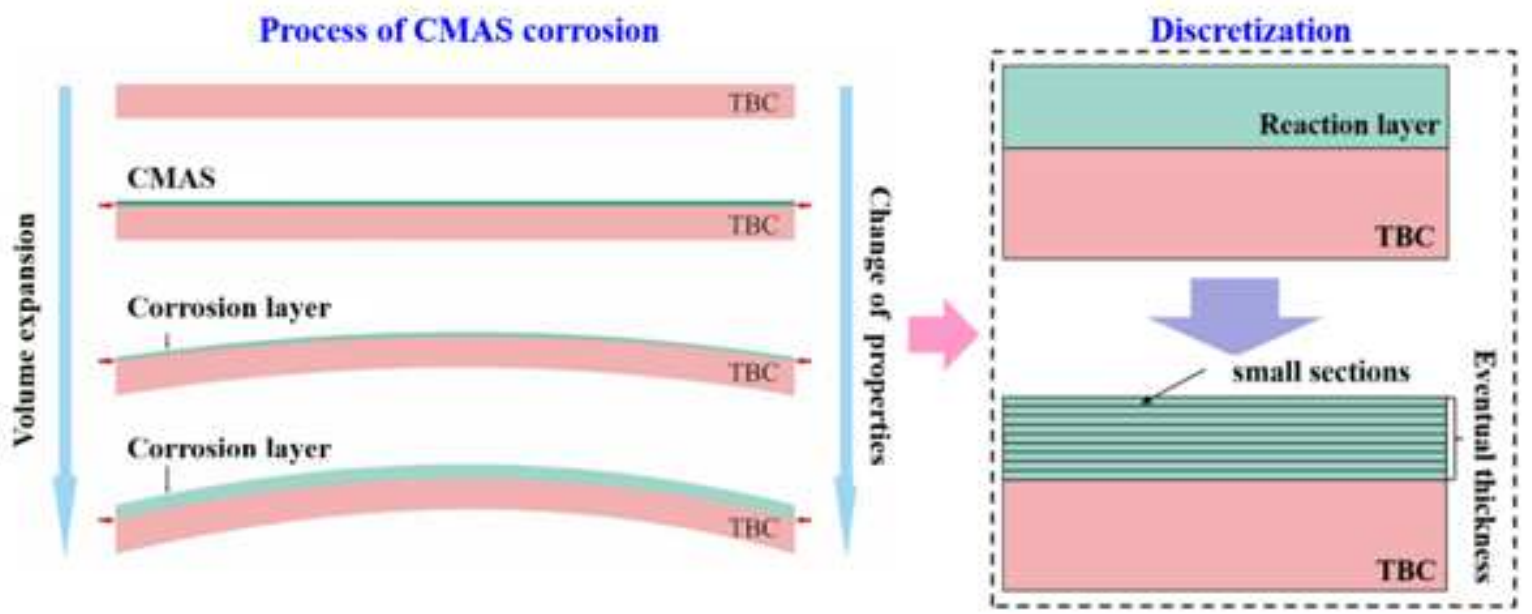

\section{Figure 4}

Corrosion model of TBC for CMAS corrosion. 

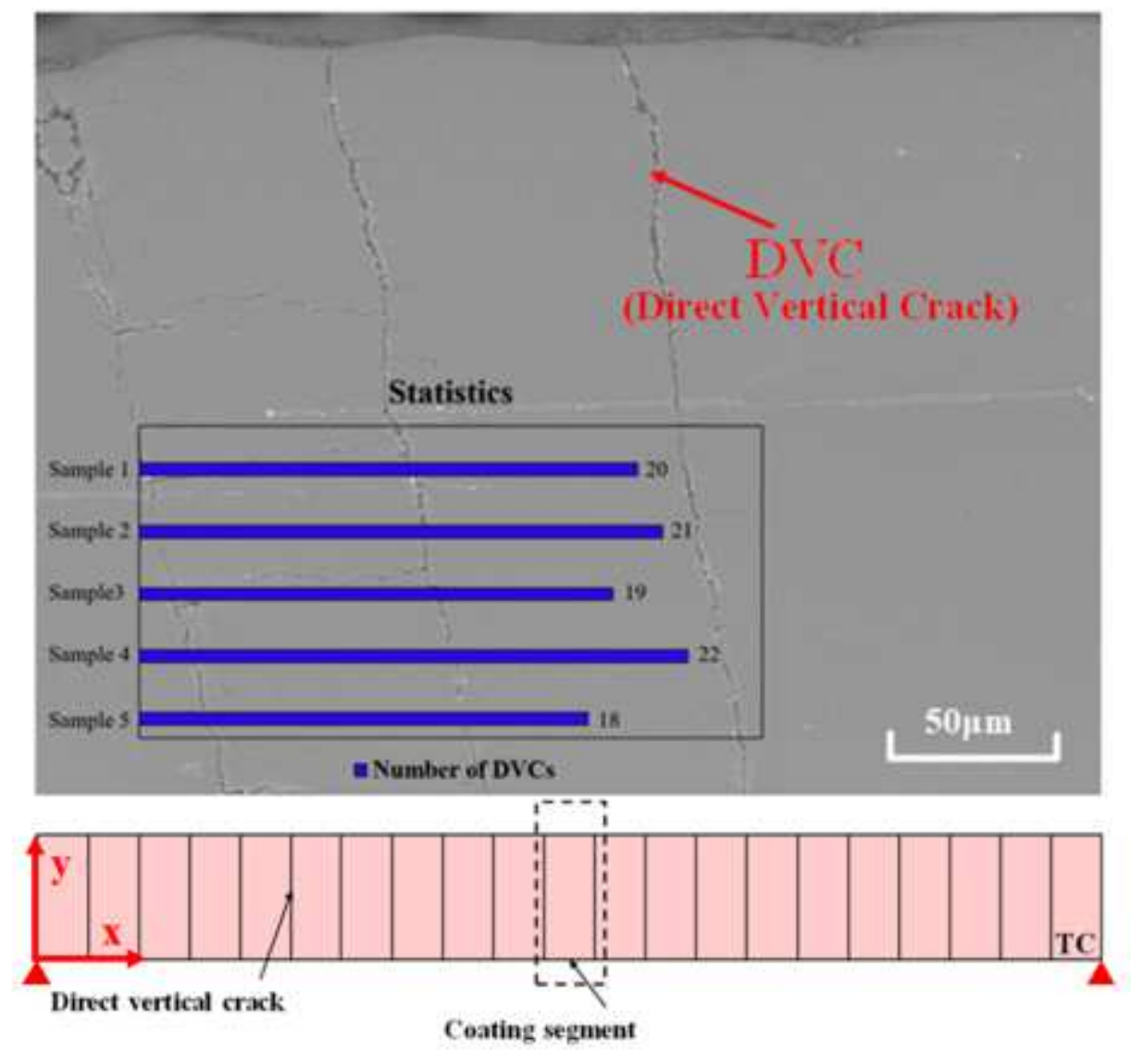

Figure 5

Illustration of the geometry of free-standing TBC with direct vertical cracks before CMAS corrosion.

(a)

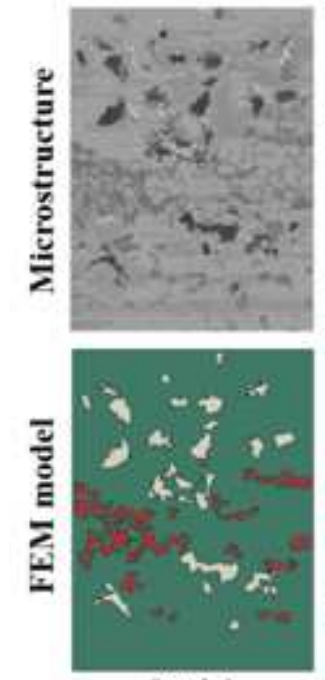

Sample 1

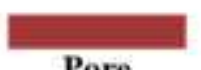

Pore
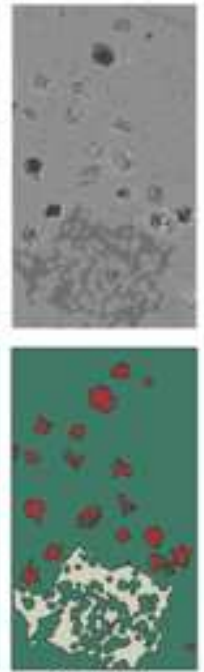

Sxmple 2
CMAS
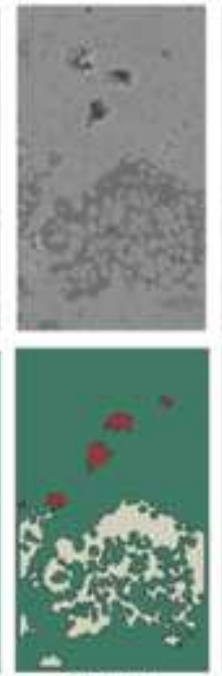

Sample 3
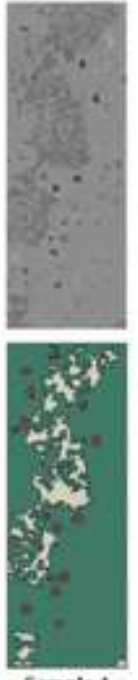

Sxmple 4

YSZ

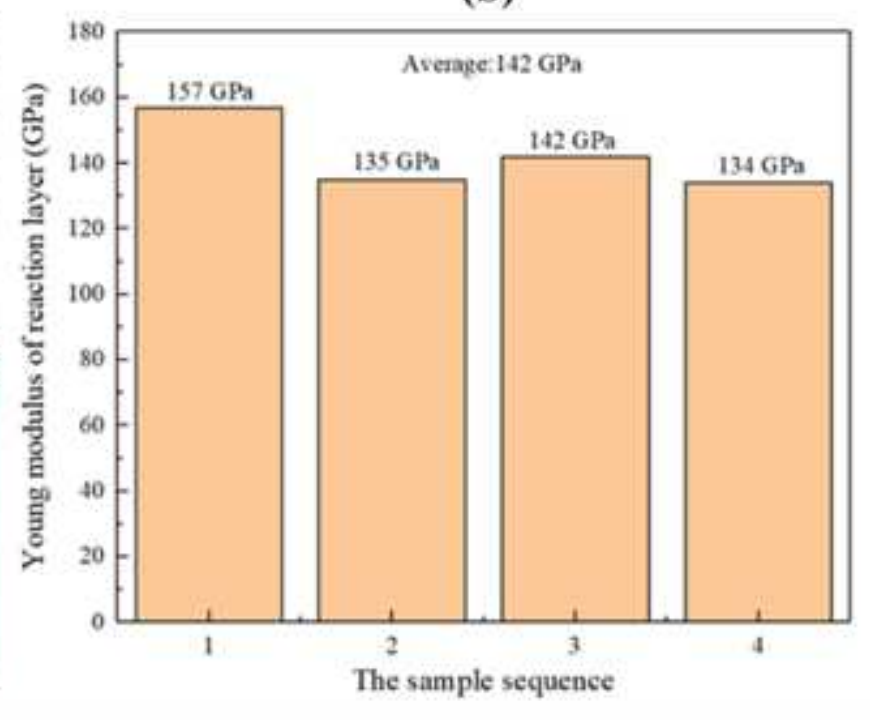

(b)

Figure 6 
(a) SEM investigation and phase evaluation of the reaction layer for the OOF analysis, (b) results of Young's modulus estimation by OOF.

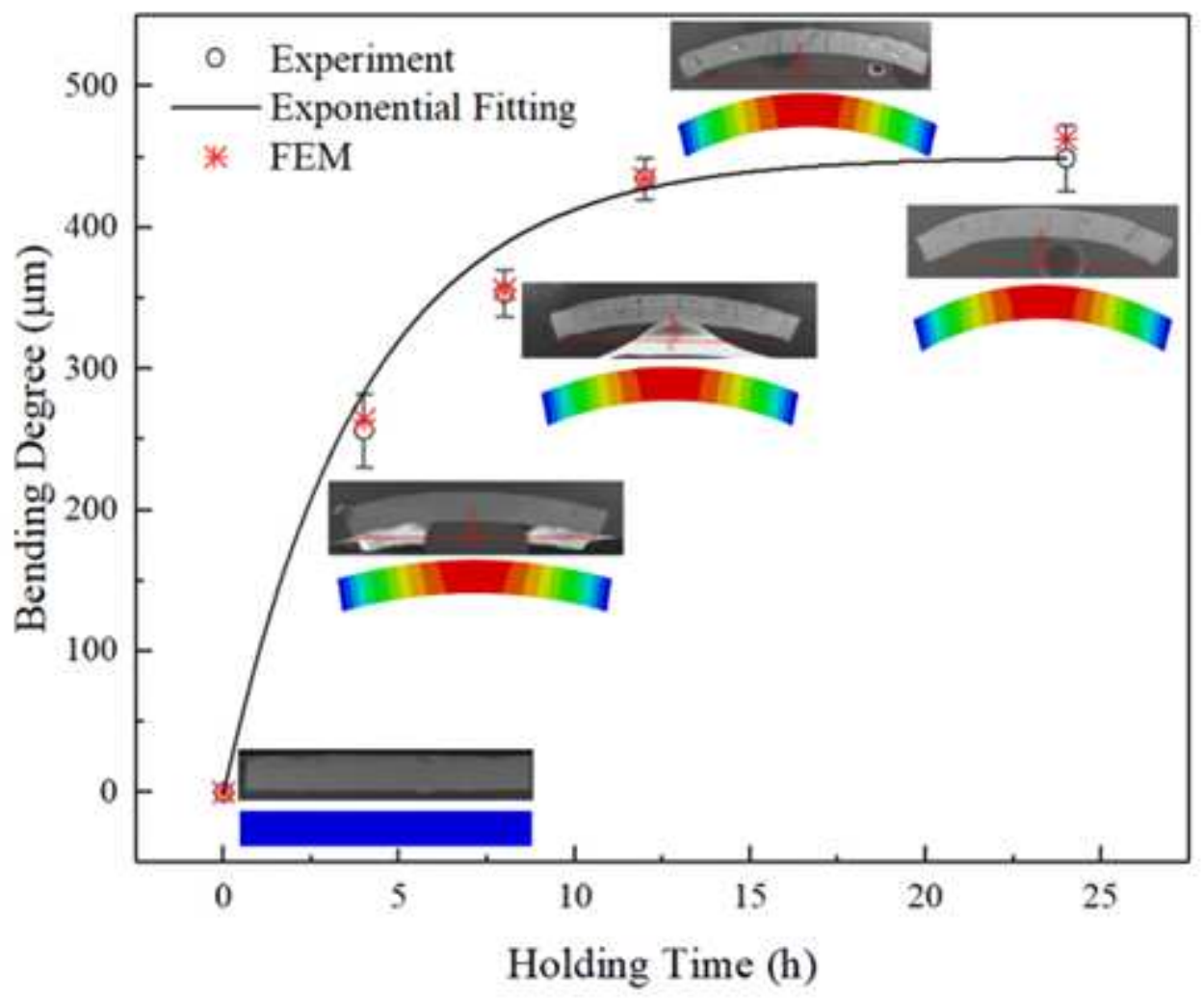

Figure 7

Experimental and simulated results of bending degree with free-standing TBC model. 


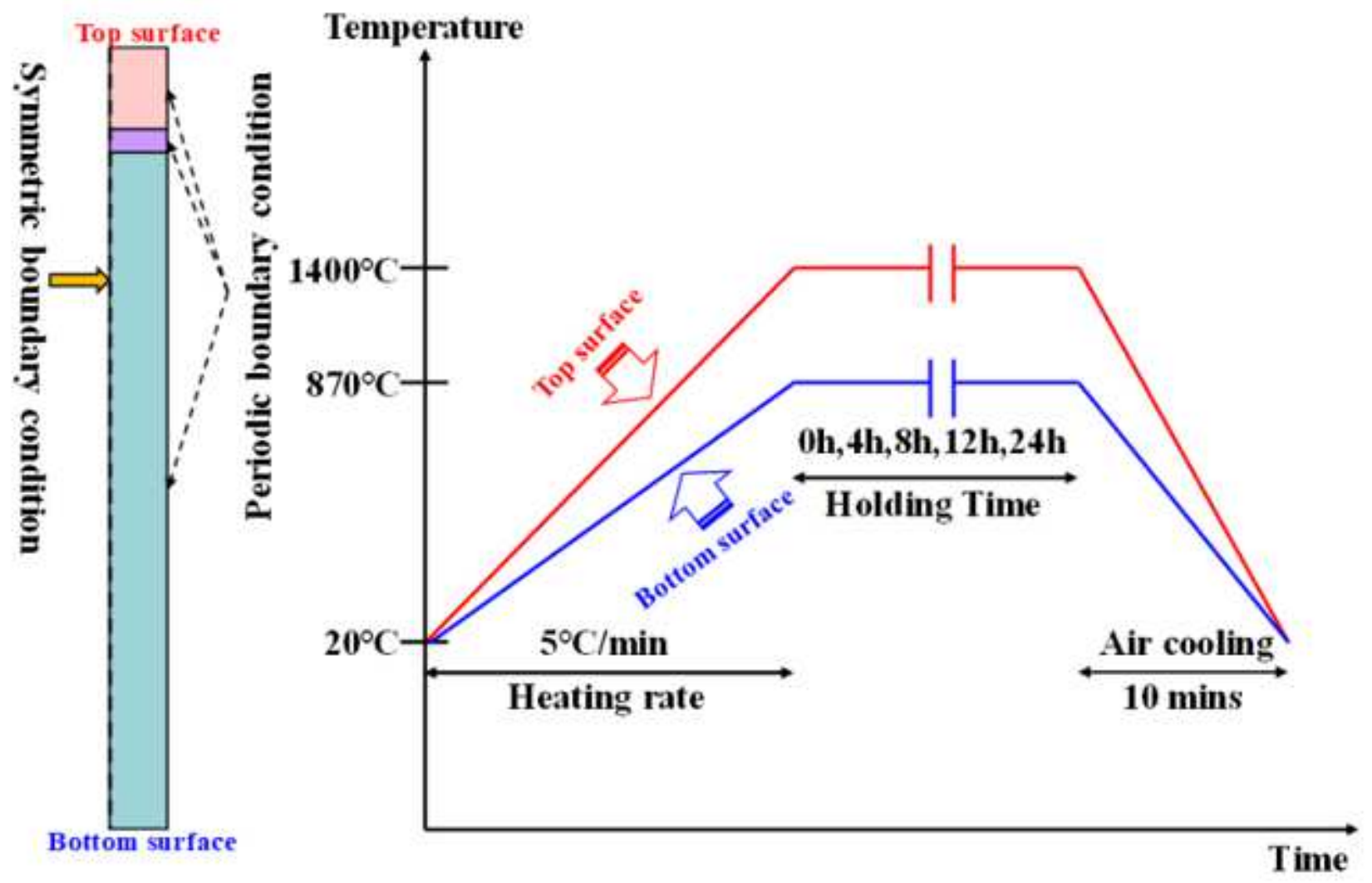

Figure 8

Illustration of the geometry of TBC before CMAS corrosion and temperature loading of the TBC model.

(a)

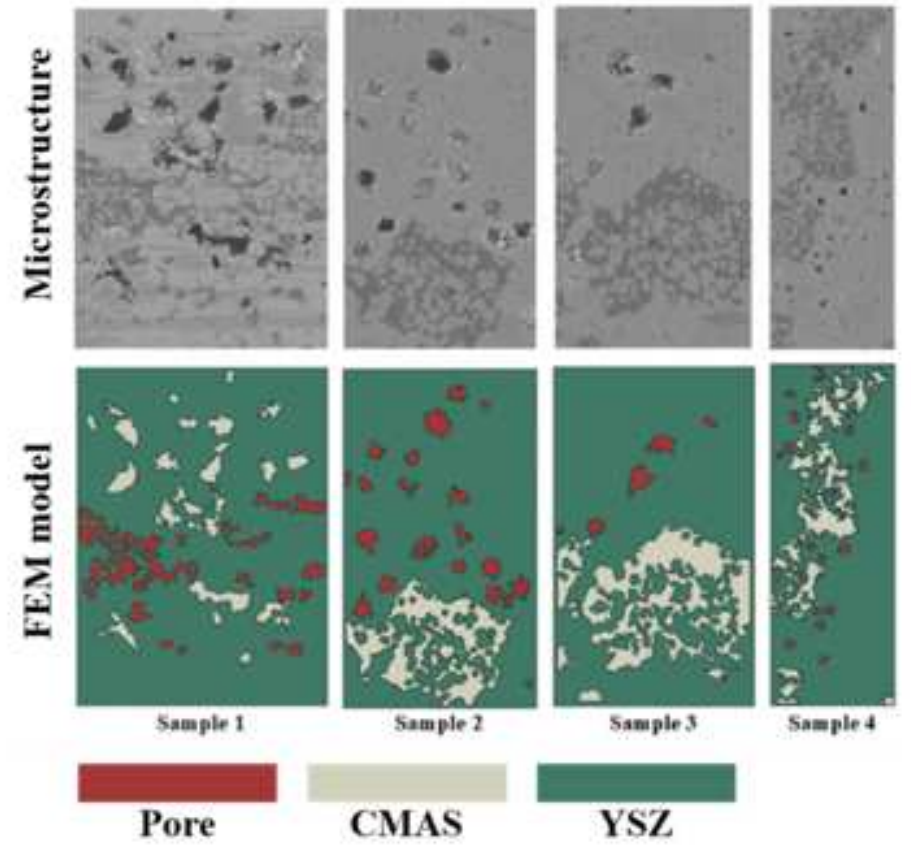

(b)

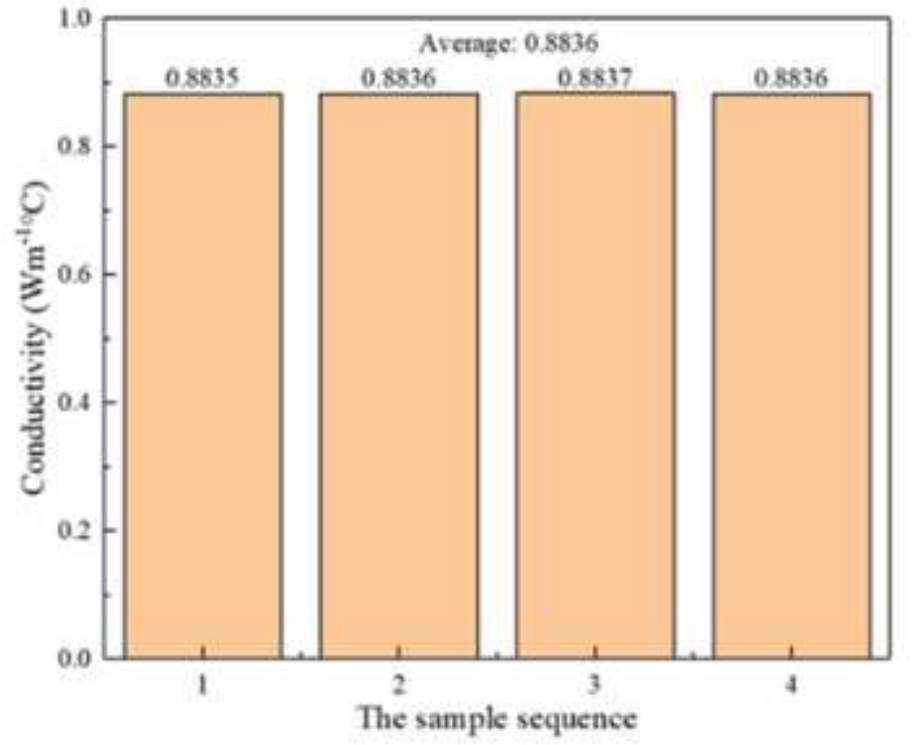

Figure 9 
Calculation of thermal conductivity for normal TBC.

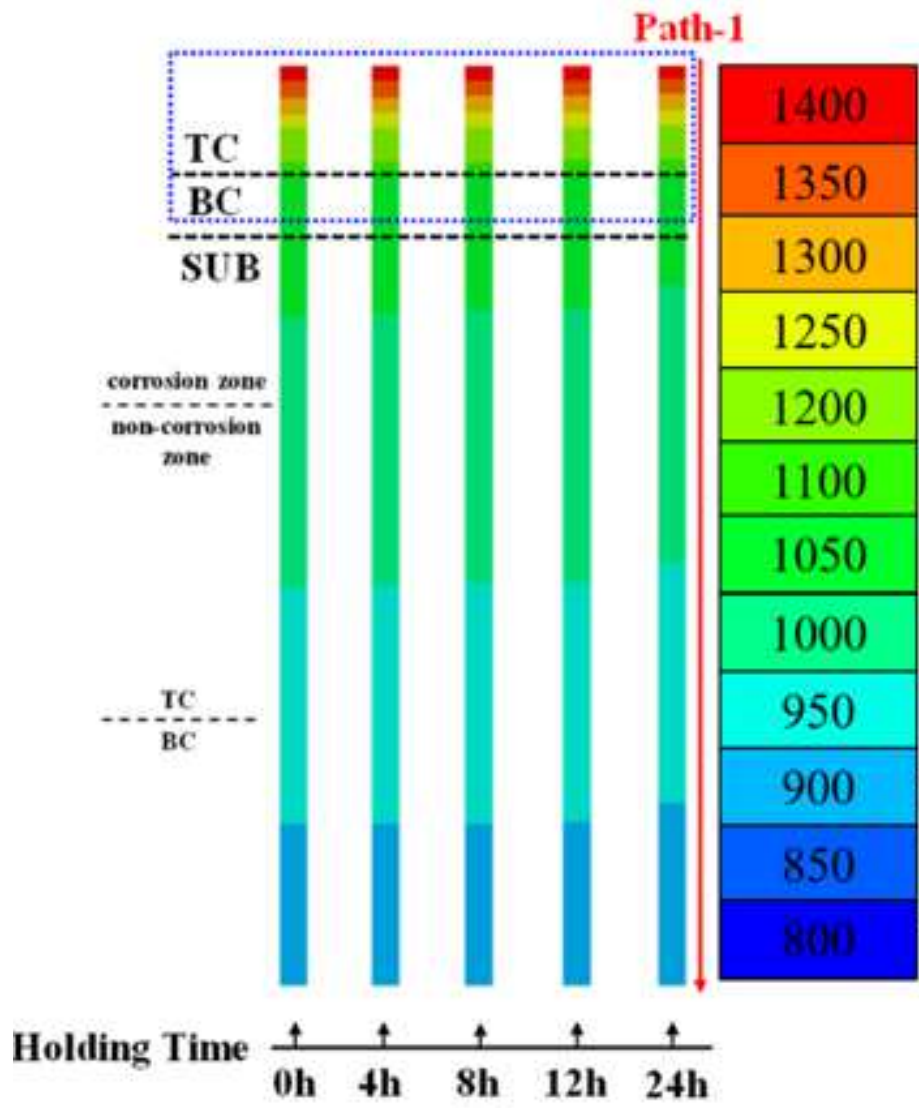

(a)

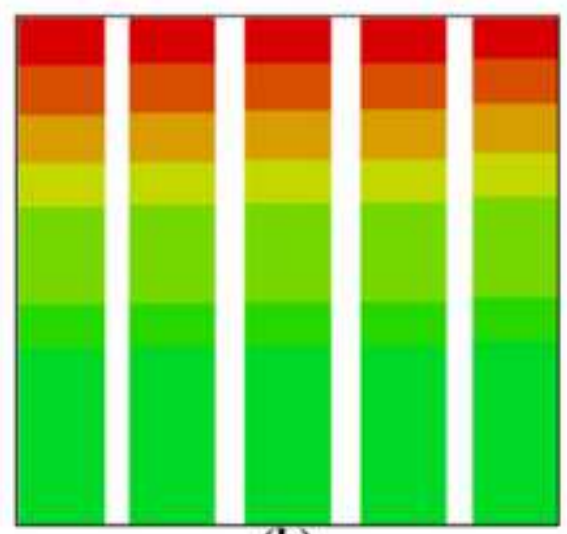

(b)

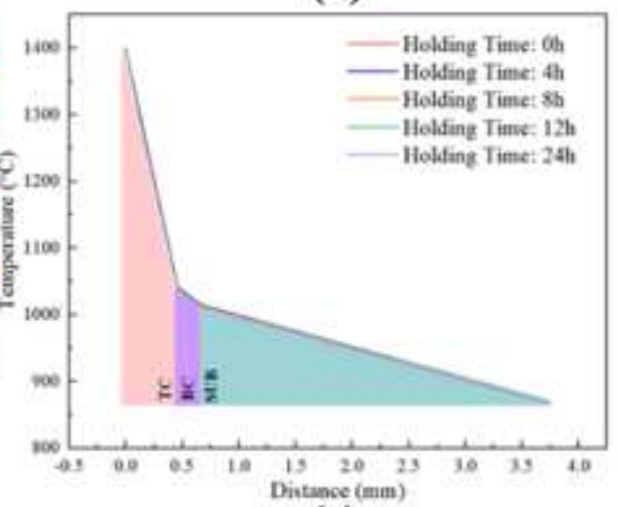

(c)

Figure 10

Distribution of temperature fields of TBC during CMAS corrosion. 
(a)

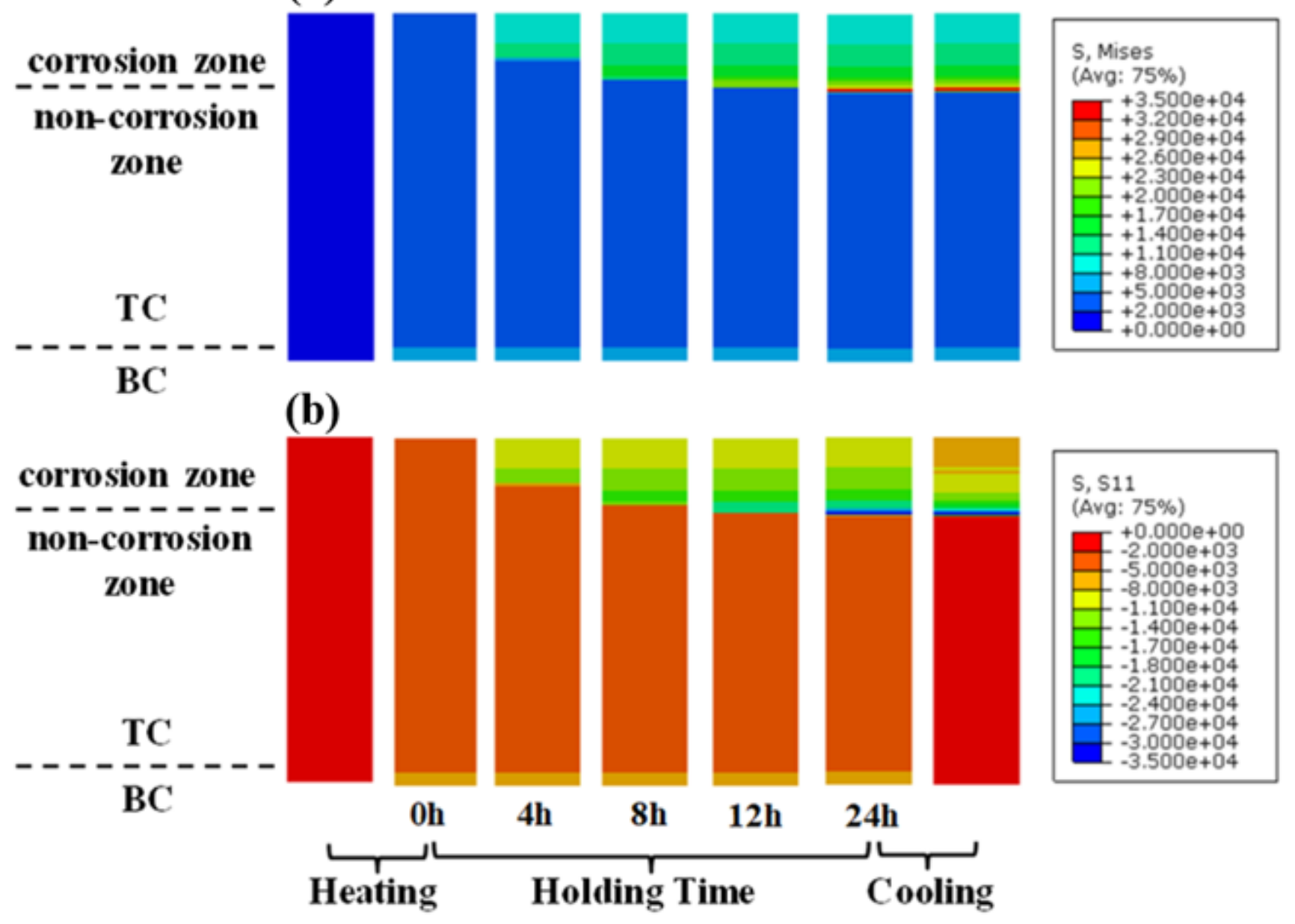

Figure 11

Two kinds of stress contour plots in different stages (a) Mises stress and (b) The principal stress at $x$ direction 

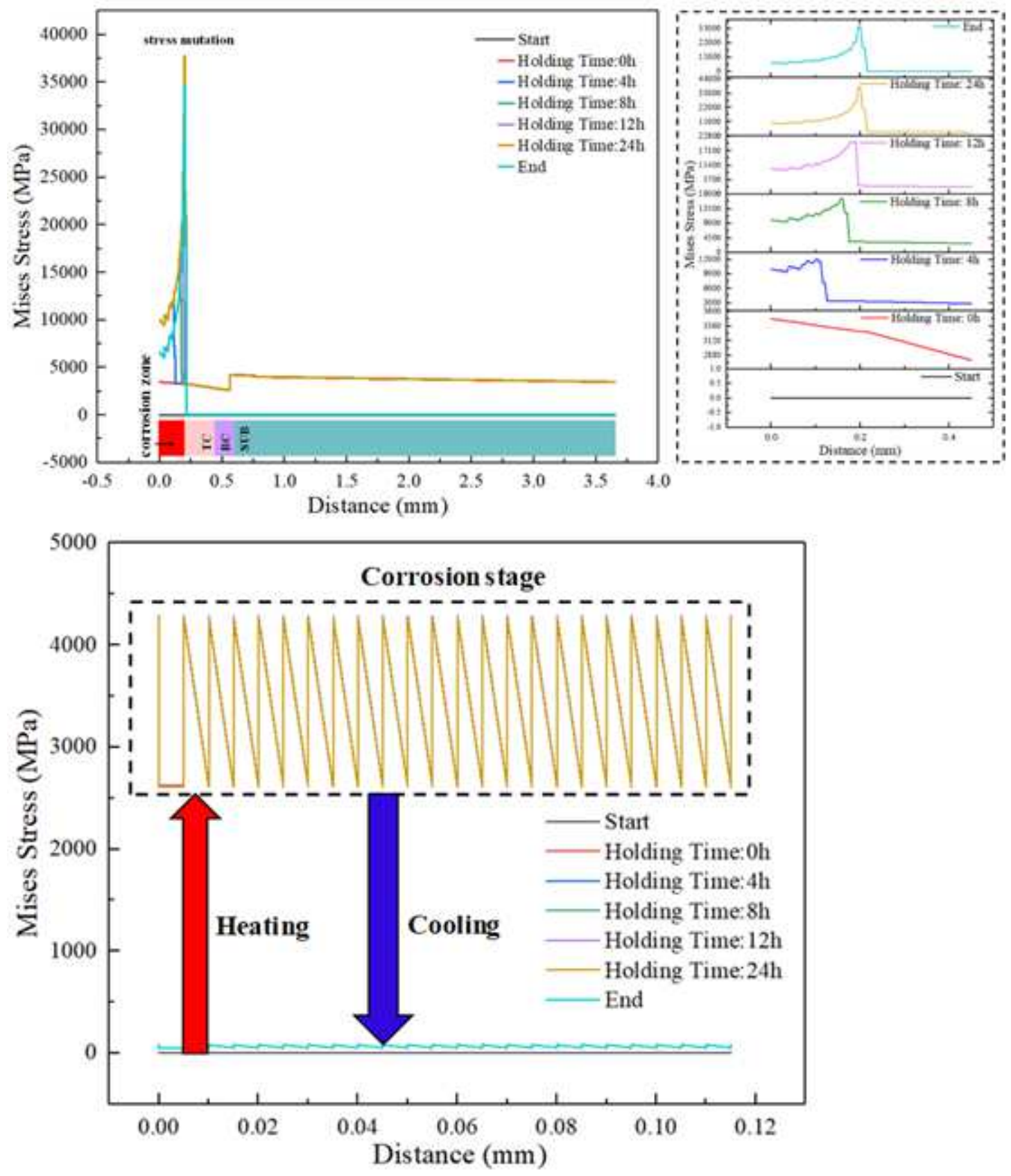

Figure 12

(a) Stress distribution along path-1(in Fig. 11) and path-2(in Fig. 12, dashed box) in different corrosion stages and (b) stress distribution along path-3 (Fig. 12) in different corrosion stages. 